\title{
Effects of Response-Independent Food Pellet Delivery on the Development of Tolerance to the Rate-Decreasing Effect of $d$ - Amphetamine in Rats
}

Christopher A. Krebs
West Virginia University

Follow this and additional works at: https://researchrepository.wvu.edu/etd

\section{Recommended Citation}

Krebs, Christopher A., "Effects of Response-Independent Food Pellet Delivery on the Development of Tolerance to the Rate-Decreasing Effect of d-Amphetamine in Rats" (2014). Graduate Theses,

Dissertations, and Problem Reports. 621.

https://researchrepository.wvu.edu/etd/621

This Dissertation is protected by copyright and/or related rights. It has been brought to you by the The Research Repository @ WVU with permission from the rights-holder(s). You are free to use this Dissertation in any way that is permitted by the copyright and related rights legislation that applies to your use. For other uses you must obtain permission from the rights-holder(s) directly, unless additional rights are indicated by a Creative Commons license in the record and/ or on the work itself. This Dissertation has been accepted for inclusion in WVU Graduate Theses, Dissertations, and Problem Reports collection by an authorized administrator of The Research Repository @ WVU.

For more information, please contact researchrepository@mail.wvu.edu. 
Effects of Response-Independent Food Pellet Delivery on the Development of Tolerance to the Rate-Decreasing Effect of $d$-Amphetamine in Rats

\author{
Christopher A. Krebs \\ Dissertation submitted to the Eberly College of Arts and Sciences \\ at West Virginia University \\ in partial fulfillment of the requirements \\ for the degree of \\ Doctor of Philosophy \\ In \\ Psychology
}

Karen G. Anderson, Ph.D., Committee Chairperson

Elizabeth Kyonka, Ph.D.

Michael Perone, Ph.D.

Steven Kinsey, Ph.D.

Stan Hileman, Ph.D.

Department of Psychology

Morgantown, West Virginia

2014

Keywords: $d$-Amphetamine, Behavioral Tolerance, Rats, Environmental Enrichment 


\begin{abstract}
Effects of Response-Independent Food Pellet Delivery on the Development of Tolerance to the Rate-Decreasing Effect of $d$-Amphetamine in Rats
\end{abstract}

\title{
Christopher A. Krebs
}

The extent to which initial drug administration decreases the ability of an organism to obtain reinforcement can affect the development of behavioral tolerance. Environmental enrichment affects many drug-related phenomena, but its effects on the development of tolerance are not clear. The present study examined how enriching the environment by providing non-contingent food pellets during experimental sessions affects the development of tolerance to a dose of $d$ amphetamine that produces a loss in reinforcement. Lever pressing for food pellets was maintained under a multiple schedule consisting of two variable-interval (VI) 60-s components. One component was enriched by providing food pellets non-contingently under a variable-time (VT) 120-s schedule for rats in the Less-Enriched Group $(n=6)$ and a VT 30-s schedule for rats in the More-Enriched Group $(n=6)$. Effects of a range of doses of $d$-amphetamine (0.1 to 3.0 $\mathrm{mg} / \mathrm{kg}$ ) were assessed before (acute) and during (chronic) repeated injections of a dose that reduced the number of food pellets earned by at least 50\% from sessions in which saline was tested acutely. There was a dose-dependent decrease in lever pressing, and relatively large doses were required to decrease the number of food pellets earned. Tolerance developed to a similar extent between components with and without non-contingent food pellets for rats in both groups. These results indicate that enriching the environment by providing non-contingent food pellets during experimental sessions does not differentially affect the development of tolerance. 


\section{Acknowledgments}

I would like to thank Karen Anderson, Elizabeth Kyonka, Michael Perone, Steve Kinsey, and Stan Hileman for taking the time to serve on my dissertation committee and for their suggestions regarding the preparation of this manuscript. I am especially thankful to Karen for serving as my advisor for the past six years and for her help in shaping me into the behavioral scientist that I am today. I would also like to thank J. Adam Bennett for teaching me how perform the response-bout analyses. 
Table of Contents

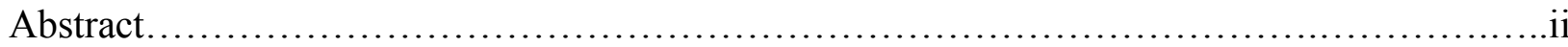

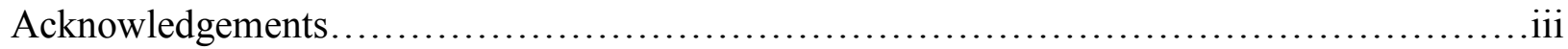

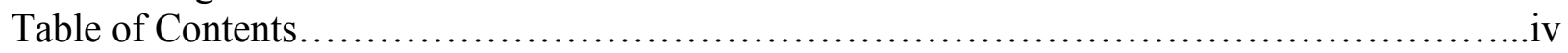

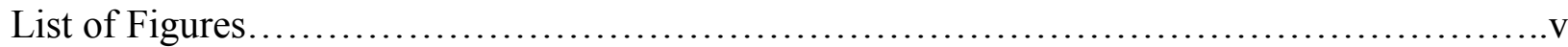

List of Tables.........................................................................

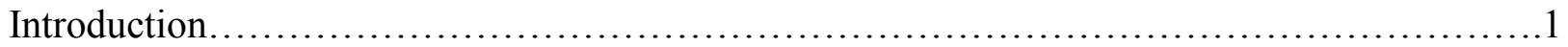

Drug Tolerance................................................................. 1

Response-Bout Analysis.......................................................2

Statement of the Problem............................................................ 10

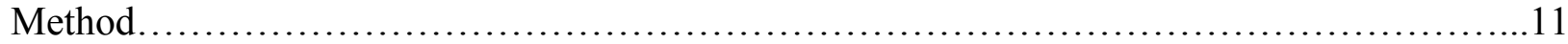

Subjects...................................................................

Apparatus............................................................................

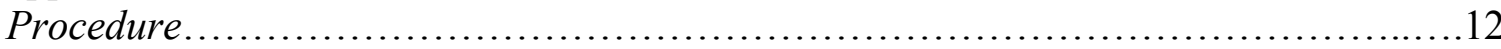

Pharmacological Regimen......................................................

Additional Manipulations...................................................... 17

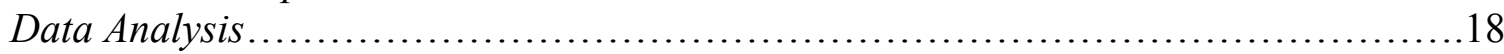

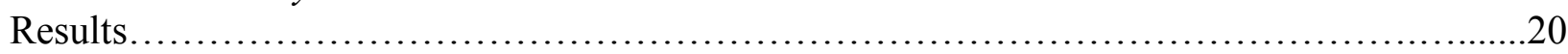

Response-rate Analysis....................................................21

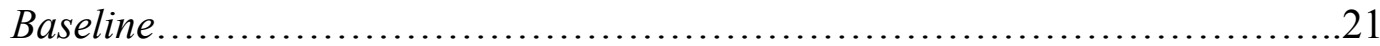

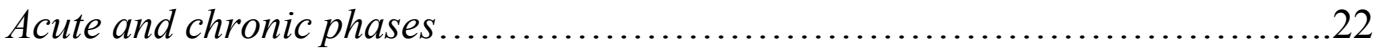

Response-bout Analysis....................................................40

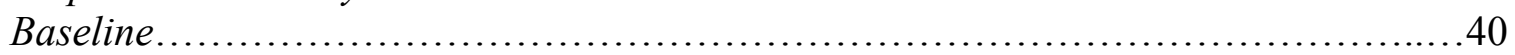

Acute and chronic phases...............................................41

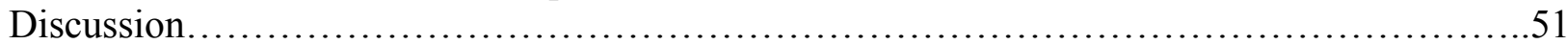

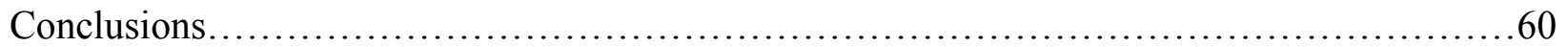

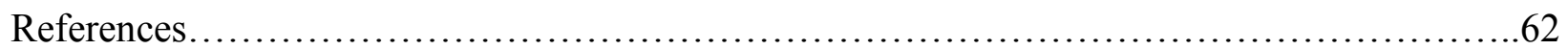




\section{List of Figures}

Figure 1. Sample log-survivor function (solid line) with the fitted double-exponential equation (dashed line). See text for Equation 1. The initial decline in the function, represented by point $w$, is indicative of responses with shorter IRTs (i.e., within-bout responses). The more gradual decline in the function, represented by point $b$, is indicative of responses with longer IRTs (i.e., bout-initiation responses). Parameter estimates and the goodness of fit $\left(r^{2}\right)$ of fitted equation are shown in the lower left. $W$ is the estimated within-bout rate (responses/s) and $b$ is the estimated

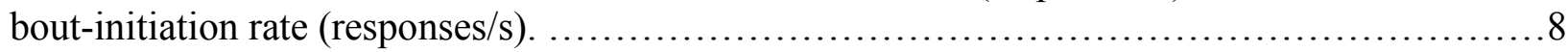

Figure 2. Lever presses/min averaged across the last six stable baseline sessions for both components of the multiple schedule for rats in both groups. Lever presses in components without non-contingent food pellets are depicted by the closed bars. Lever presses in components with non-contingent food pellets are depicted by the open bars for rats in the LessEnriched Group, and by the grey bars for rats in the More-Enriched Group. Error bars represent

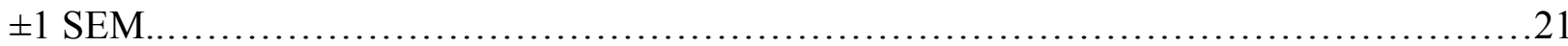

Figure 3. Dose-effect functions across components (columns) for each rat (rows) in the LessEnriched Group. Lever-press rates are expressed as percent of lever-press rates from sessions in which saline was injected. The repeated dose of $d$-amphetamine is indicated in parenthesis next to rat identification. Data from the acute phase are indicated by open circles; closed circles represent data from the chronic phase. Error bars represent \pm 1 SEM. Dashed horizontal lines indicate no change from when saline was injected. During the chronic phase, data for the repeated dose were taken from sessions the day before probe sessions; hence more determinations for the repeated dose are included in the mean than for other doses.

Figure 4. Dose-effect functions across components (column) for each rat (rows) in the MoreEnriched Group. Lever-press rates are expressed as percent of lever-press rates from sessions in which saline was injected. The repeated dose of $d$-amphetamine is indicated in parenthesis next to rat identification. Data from the acute phase are indicated by open circles; closed circles represent data from the chronic phase. Error bars represent \pm 1 SEM. Dashed horizontal lines indicate no change from saline injections. During the chronic phase, data for the repeated dose were taken from sessions the day before probe sessions; hence more determinations for the repeated dose are included in the mean than for other doses.............................. 26

Figure 5. The ratio between the area under the curve (AUC) of the dose-effect function from the chronic phase and the acute phase for rats in both groups. Ratios for components without noncontingent food pellets are depicted by the closed bars; ratios for components with noncontingent food pellets are depicted by the open bars for rats in the Less-Enriched Group and by the grey bars for rats in the More-Enriched Group. The dashed line at 1.0 represents no change in AUC values from the acute phase. Error bars represent \pm 1 SEM.........................28 
Figure 6. Mean lever presses/min from sessions in which the individually selected repeated dose of $d$-amphetamine was injected for the acute, chronic, and repeated phases for each rat (rows) in the Less-Enriched Group. The repeated dose of $d$-amphetamine is indicated in parenthesis next to rat identification. Data from components without non-contingent food pellets are indicated by open circles; closed circles represent data from components with non-contingent food pellets.

Error bars represent \pm 1 SEM. Data for the acute and chronic phases are to the left of the verticaldashed line and represented by $\mathrm{A}$ and $\mathrm{C}$, respectively. For the acute phase, data are from all injections of the repeated dose. For the chronic phase, data are from sessions conducted the day before probe sessions. Data for the repeated phase are to the right of the vertical-dashed line, and are from the first 45 sessions in which the repeated dose was injected. The first 6 sessions of the repeated phase for rat L1 are omitted because a smaller repeated dose (i.e., $1.0 \mathrm{mg} / \mathrm{kg}$ ) was injected during those sessions (see text for details). Note that the $y$-axis is scaled differently for

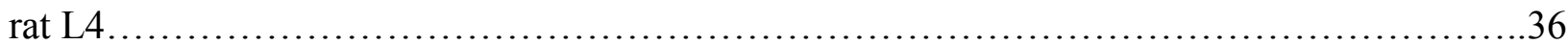

Figure 7. Mean lever presses/min from sessions in which the individually selected repeated dose of $d$-amphetamine was injected for the acute, chronic, and repeated phases for each rat (rows) in the More-Enriched Group. The repeated dose of $d$-amphetamine is indicated in parenthesis next to rat identification. Data from components without non-contingent food pellets are indicated by open circles; closed circles represent data from components with non-contingent food pellets. Error bars represent \pm 1 SEM. Data for the acute and chronic phases are to the left of the verticaldashed line and represented by A and C, respectively. For the acute phase, data are from all injections of the repeated dose. For the chronic phase, data are from sessions conducted the day before probe sessions. Data for the repeated phase are to the right of the vertical-dashed line, and are from the first 45 sessions in which the repeated dose was injected.....................38

Figure 8. Log-survivor functions of IRT distributions collapsed across the last six stable baseline sessions for rats in the Less-Enriched Group. Log proportions of IRTs are plotted as a function of IRT Duration (s). Solid lines represent lever presses in the component without noncontingent food pellets. Dashed lines represent lever presses in the component with noncontingent food pellets. Fit lines represent the best fitting double-exponential equation. The $x$ -

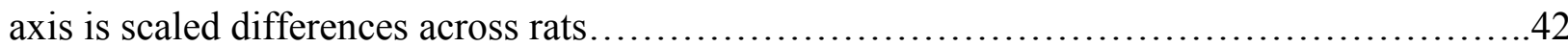

Figure 9. Log-survivor functions of IRT distributions collapsed across the last six baseline sessions for rats in the More-Enriched Group. Log proportions of IRTs are plotted as a function of IRT Duration (s). Solid lines represent lever presses in the component without non-contingent food pellets. Dashed lines represent lever presses in the component with non-contingent food pellets. Fit lines represent the best fitting double-exponential equation. The $x$-axis is scaled differences across rats.................................................................. 44 


\section{List of Tables}

Table 1. The Number of Injections of Saline and Doses of d-Amphetamine Tested during the Acute and Chronic Phases for Rats in both Groups.......................................16

Table 2. Lever-Presses/min ( \pm 1 SEM) averaged across the Last Six Stable Baseline Sessions for the Multiple Schedule Components for Rats in both Groups..............................22

Table 3. Lever Presses/min ( \pm 1 SEM) averaged across Sessions in which Saline and dAmphetamine were Tested during the Acute and Chronic Phases for the Multiple Schedule Components for Rats in the Less-Enriched Group.......................................29

Table 4. Lever Presses/min ( \pm 1 SEM) averaged across Sessions in which Saline and dAmphetamine were Tested during the Acute and Chronic Phases for the Multiple Schedule Components for Rats in the More-Enriched Group.

Table 5. Area Under the Curve of the Dose-Effect Functions for the Acute and Chronic Phases for the Multiple Schedule Components for Rats in both Groups.

Table 6. Estimates of Bout-Initiation (b) and Within-Bout (w) Responses/s and $\mathrm{r}^{2}$ values for the Best Fitting Double-Exponential Function during Baseline for the Multiple Schedule Components for Rats in both Groups.

Table 7. Estimates of Bout-Initiation (b) and Within-Bout (w) Responses/s and $\mathrm{r}^{2}$ values from the Best Fitting Double-Exponential Function for the Doses of Saline and d-Amphetamine Tested during the Acute and Chronic Phases for the Multiple Schedule Components for Rats in the Less-Enriched Group

Table 8. Estimates of Bout-Initiation (b) and Within-Bout (w) Responses/s and $\mathrm{r}^{2}$ values for the Best Fitting Double-Exponential Function for the Doses of Saline and d-Amphetamine Tested during the Acute and Chronic Phases for the Multiple Schedule Components for Rats in the More-Enriched Group. 
Effects of Response Independent Food Pellet Delivery on the Development of Tolerance to the Rate Decreasing Effect of $d$-Amphetamine in Rats

When a drug is administered repeatedly, larger doses of that drug may be required to obtain the initial effects. This effect is referred to as tolerance and it is a common consequence of repeated drug administration. It is important to examine why tolerance develops for several reasons. First, therapeutic effects of some drugs (e.g., antidepressants) are not observed until after that drug has been administered repeatedly, while tolerance to other effects (e.g., nausea) of that drug may develop after one or two administrations. Why tolerance develops rapidly to some effects of a drug and not to others is not entirely clear. Second, repeated drug administration may contribute to the development of substance-abuse disorders (American Psychiatric Association, 2000; World Health Organization, 2011). Substance abusers often report needing larger doses of a drug to achieve a given effect than they did when they first used the drug. Increasing our understanding of the conditions under which tolerance develops may provide information about why some people who repeatedly use a given drug develop a substance-abuse problem, while others do not.

The development of tolerance can be mediated by several variables such as changes in the number or sensitivity of drug receptors (i.e., pharmacodynamic factors) and alterations in the rate at which a drug is metabolized or excreted (i.e., pharmacokinetic factors). Although important, these physiological factors alone do not explain why tolerance develops to some behavioral effects of a drug and not others across organisms with equivalent drug exposure. In these cases, environmental variables such as whether the drug interferes with the ability of the organism to obtain reinforcement can impact the development of tolerance (for reviews see Branch, 1991; Corfield-Summer and Stolerman, 1978; Goudie and Emmett-Oglesby, 1989; 
Stewart and Badiani, 1993; Wolgin, 1989). Animal models are often used to study the conditions under which tolerance develops because they afford greater control over the interaction between the features of the environment and the drug-administration regimen.

One way to assess the development of tolerance using animal models is to examine how dose-effect functions change during repeated drug administration. Dose-effect functions are often used to show how different doses of a drug affect a particular behavior. The initial, or acute, effects of a drug are determined by testing different doses of the drug once or twice a week. After the acute effects of a drug are determined, a particular dose of that drug is selected to be administered for a set number of sessions. After a specific number of repeated drug administrations, the dose of the drug being administered repeatedly is substituted once or twice a week with doses of the drug that were tested during the acute phase. To determine whether or not tolerance occurred, the acute and chronic dose-effect functions are compared. If tolerance developed, larger doses of the drug would be needed to produce the initial effects of the drug. This would result in a rightward shift of the chronic dose-effect function compared to the acute dose-effect function. If sensitization, the opposite of tolerance, developed, the initial effects of the drug would be produced by smaller doses, and result in a leftward shift of the chronic doseeffect compared to the acute dose-effect function.

The impact that environmental variables can have on the development of tolerance was demonstrated in a seminal study by Schuster et al. (1966). In this study, lever pressing for food pellets by three rats was maintained under a multiple schedule consisting of a fixed-interval (FI) 30-s component and a differential-reinforcement-of-low-rate (DRL) 30-s component. Each component in a multiple schedule is associated with a unique stimulus and is presented at least once during a session. In the FI component, the first response that occurred after $30 \mathrm{~s}$ was 
reinforced. Responses that occurred before $30 \mathrm{~s}$ were recorded, but had no other programmed consequence. In the DRL component, the first response to occur $30 \mathrm{~s}$ after the most recent response was reinforced. Responses that occurred within $30 \mathrm{~s}$ of the last response postponed reinforcement by an additional $30 \mathrm{~s}$. For two rats, $d$-amphetamine initially increased response rates in both components. This decreased the number of food pellets earned in the DRL component, not in the FI component. Tolerance for these two rats occurred only in the DRL component. For the other rat, $d$-amphetamine initially decreased response rates in the FI component. This decreased the number of food pellets earned in that component, and tolerance occurred only in that component for this rat. Had the development of tolerance been due solely to physiological factors, tolerance would have occurred to an equal extent, or not at all, in both components. Because tolerance occurred only in components in which $d$-amphetamine decreased the number of food pellets earned, Schuster et al. proposed that tolerance to the behavioral effects of a drug can be mediated by whether that drug interferes with the ability of an organism to obtain reinforcement. This idea has since become known as the reinforcement-loss hypothesis (Schuster, 1978).

Although there is extensive empirical support for the reinforcement-loss hypothesis, several studies have shown that reinforcement loss alone is not sufficient for the development of tolerance (for reviews, see Branch, 1991; Wolgin, 1989). In these studies, the development of tolerance was influenced by other features of the environment such as the type and parameters of the reinforcement schedules used to maintain behavior. For example, Hoffman et al. (1987) maintained key pecking for access to grain by pigeons under a multiple schedule that consisted of a fixed-ratio (FR) 5, FR 25, and FR 125 component. The ratio value in FR schedules specifies the number of responses required for reinforcement. In the FR 5 component, for example, five 
responses were required for reinforcement. Injections of cocaine dose dependently decreased response rates in each FR component. This decreased the amount of grain earned in each component. Tolerance developed to a greater extent in the small FR component than in the larger FR components. These results highlight a limitation of the reinforcement-loss hypothesis because tolerance did not occur, or it developed to a lesser extent, in the larger FR components compared to the small FR components, despite there being a decrease in the amount of grain earned in each component (see also Branch, 1990; Genovese et al., 1988; Nickel et al., 1993; Smith, 1986a, 1990; van Haaren and Anderson, 1994).

If reinforcement loss is considered in the context of the other schedules of reinforcement during an experimental session, then it is possible that the schedule-parameter-value related tolerance observed by Hoffman et al. (1987) might have been due to the fact that reinforcement loss was greater in the small FR component compared to the larger FR components (Nickel et al., 1993; Porritt et al., 2007; but see Schama and Branch, 1989). Support for this interpretation comes from a study reported by Smith (1986b) who showed that the amount of reinforcement loss under one schedule of reinforcement compared to another can impact the development of tolerance. In this study, lever pressing for food pellets by rats was maintained under a multiple schedule consisting of a random-ratio (RR) 40 component and a DRL 30-s component. In the RR component, each response had the same probability of reinforcement. Under a RR 40 schedule that probability was 0.025 . Initial injections of $d$-amphetamine decreased response rates in the RR component and increased response rates in the DRL component. Reinforcement loss occurred to a greater extent in the RR component compared to the DRL component, and tolerance was observed only in the RR component. In a subsequent condition, the RR component was removed and rats were exposed to just the DRL component. When this 
happened, tolerance under the DRL schedule developed immediately. During the final condition the tolerance observed under the DRL schedule disappeared immediately when the RR component was reinstated. The ability to turn tolerance on or off by adding or removing a particular schedule of reinforcement indicates that tolerance is sensitive to the relative amount of reinforcement obtained, or lost, under one reinforcement schedule compared to another.

In a typical operant-conditioning chamber there are a variety of sources of reinforcement available during an experimental session. For rats, these sources may consist of things such as food pellets, which are often used to reinforce a target behavior such as a lever press. Other sources of reinforcement may be obtained from behavior extraneous to the target operant such as grooming, sniffing, or interacting with other features of the operant-conditioning chamber. The amount of reinforcement derived from behavior extraneous to the target behavior can vary across individual subjects on a lean-to-rich continuum based on subtle environmental and biological differences. If the relative amount of reinforcement obtained under one reinforcement schedule compared to another influences the development of tolerance (e.g., Smith, 1986b), then the amount of reinforcement derived from behavior extraneous to the target behavior may also influence the development of tolerance. If so, this may account for some of the variability in tolerance development reported between studies and across subjects within the same study (Dallery and Lancaster, 1999; Hoffman et al., 1987; Hughes et al., 1996; 2005; Nickel et al., 1993; Stafford and Branch, 1996; Wolgin, 1989; 2000).

Although it is difficult to all possible responses and sources of reinforcement, they can be estimated using Herrnstein's (1970) single-alternative matching equation which has described choice between two mutually exclusive response alternatives, one being the target response and 
the other being the sum of all other responses that could occur in a variety of contexts (McDowell, 1988; Reed and Kaplan, 2011). In this equation:

$$
R=k\left(\frac{r}{r+R_{o}}\right)
$$

$R$ represents the absolute rate of the target response and $r$ represents the absolute rate of reinforcement for that response. The parameters $k$ and $R_{\mathrm{o}}$ are free parameters derived by fitting a hyperbola and represent the sum of possible target and non-target responses $(k)$ and the sum of all reinforcement derived from the non-target responses $\left(R_{\mathrm{o}}\right)$. Importantly, the parameter $\mathrm{R}_{\mathrm{o}}$ has been shown to increase when alternative sources of reinforcement are introduced during experimental sessions and decrease when they are removed. Smaller values of $R_{\mathrm{o}}$ are therefore thought to reflect a more impoverished environmental context while larger values reflect a more enriched environmental context (for reviews see Davison and McCarthy, 1988; Williams, 1988; but see Dallery et al., 2000; Dallery and Soto, 2004).

Dallery and Lancaster (1999) found that the environmental context, as measured by $R_{\mathrm{o}}$, was correlated with the development of tolerance. In their study, lever pressing for food pellets by rats was maintained under a multiple schedule consisting of five different variable-interval (VI) components. In the VI components, the first response to occur after an average amount of time, specified by the value of the VI schedule, resulted in reinforcement. Herrnstein's (1970) single-alternative matching equation described well the changes in response rates across the different VI components. Values of $R_{\mathrm{o}}$ obtained during baseline conditions varied substantially across rats, but were related to the development of tolerance. Tolerance developed to a greater extent for rats that had smaller values of $R_{\mathrm{o}}$ (i.e., a more impoverished environmental context) compared to rats that had larger values of $R_{\mathrm{o}}$ (i.e., a more enriched environmental context). Tolerance also developed to a greater extent in components with smaller VI schedule values than 
in components with larger schedule values. Because reinforcement loss was greater in the components with smaller VI schedule values compared to components with larger schedule values, it is unclear if the development of tolerance was due to differences in the degree to which reinforcement rate decreased across the different VI components, or to differences in the economic context. In the absence of direct manipulation, the role that the environmental context plays in tolerance development is not clear.

One way to manipulate the environmental context (i.e., $R_{\mathrm{o}}$ ), is to provide food independent of behavior (i.e., non-contingently) during experimental sessions (for a review see Burgess and Wearden, 1986; see also Belke and Heyman, 1994; deVillers, 1977; Herrnstein, 1970; 1974; Heyman, 1983; McDowell, 1988; Nevin et al., 1990; Rachlin and Baum, 1972). For example, Rachlin and Baum found that values of $R_{\mathrm{o}}$ were systematically related to the rate at which food was provided non-contingently to pigeons that key pecked for access to grain under a VI schedule. Non-contingent food was provided after an average amount of time using a variable-time (VT) schedule. Across conditions, response rates decreased as the rate at which non-contingent food was provided increased. These changes were described well by Herrnstein's (1970) single-alternative matching equation and values of $R_{\mathrm{o}}$ increased as the rate at which non-contingent food was provided increased. Altering the rate at which non-contingent food is provided is therefore one way in which the environmental context can be experimentally manipulated.

\section{Response-Bout Analysis}

The development of tolerance to the behavioral effects of a drug is often characterized by comparing how a drug affects responding before and during repeated administration of a drug. Responding, however, sometimes occurs in bouts of responses with relatively short inter- 
response times (IRTs) separated by responses with relatively long IRTs. Shull et al. (2001) describes a method to distinguish responses with relatively short and long IRTs using logsurvivor functions of cumulative IRT distributions (see also Brackney et al., 2011; Shull, 2004). These log-survivor functions plot the proportion of IRTs longer than a particular duration as a function of IRT duration. When responding with two distinct distributions of IRTs does occur, these functions typically have a "broken-stick" appearance such as that shown in Figure 1. The declining limb on the left (segment $w$ ) represents responses with shorter IRTs (i.e., within-bout responses) while the declining limb on the right (segment $b$ ) represents responses with longer IRTs (i.e., bout-initiation responses).

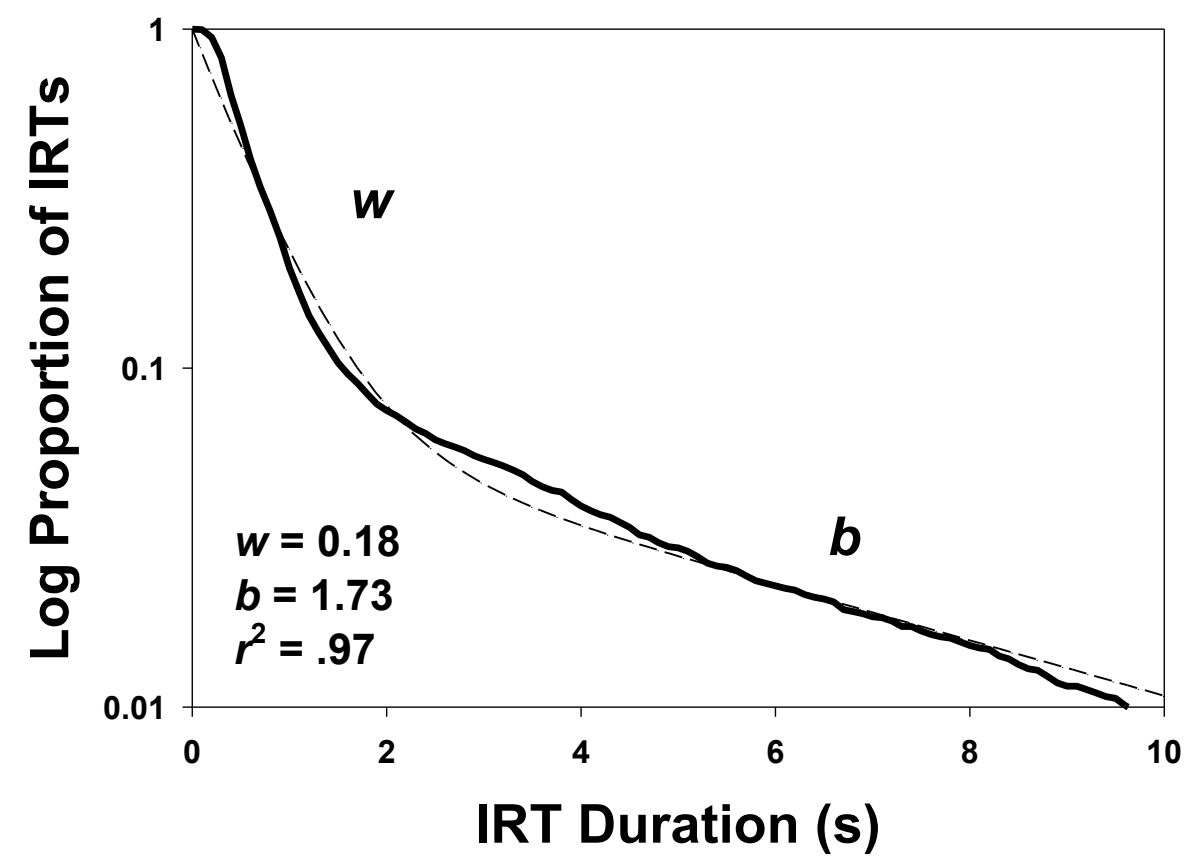

Figure 1. Sample log-survivor function (solid line) with the fitted double-exponential equation (dashed line). See text for Equation 1. The initial decline in the function, represented by point $w$, is indicative of responses with shorter IRTs (i.e., within-bout responses). The more gradual decline in the function, represented by point $b$, is indicative of responses with longer IRTs (i.e., bout-initiation responses). Parameter estimates and the goodness of fit $\left(r^{2}\right)$ of fitted equation are shown in the lower left. $W$ is the estimated within-bout rate (responses/s) and $b$ is the estimated bout-initiation rate (responses/s). 
When log-survivor functions of IRTs have this broken-stick appearance it is possible to estimate within-bout and bout-initiation rates by fitting the following double-exponential equation to the function:

$$
p(t)=(1-q) \mathrm{e}^{-\mathrm{wt}}+q e^{-b t}
$$

where $p(t)$ is the proportion of IRTs $>t(\mathrm{~s}) ;(1-q)$ is the proportion of responses that are within a bout; $e$ is the base of the natural logarithm, $w$ is the within-bout rate in responses/s; $q$ is the proportion of responses that initiation a bout; and $b$ is the bout-initiation rate in responses/s (Brackney et al., 2011; Hill et al., 2012; Johnson et al., 2009; 2011; Shull, 2004; Shull and Grimes, 2003; Shull et al., 2004).

Several studies have provided evidence that bout-initiation and within-bout rates may reflect two different aspects of responding. For example, changes in reinforcement rate and reinforcement magnitude have been shown to affect bout-initiation rates, while changes in response requirements have been shown to affect within-bout rates (Bennett et al., 2007; Brackney et al., 2011; Johnson et al., 2009; 2011; Reed, 2011; Shull, 2004; Shull et al., 2001; 2002; 2004; Shull and Grimes, 2003). Bout-initiation rates, which are sensitive to changes in reinforcer properties, are therefore thought to reflect motivational aspects of responding, while within-bout rates, which are sensitive to changes in response requirements, are thought to reflect motoric aspects of responding. If bout-initiation and within-bout rates do reflect different aspects of responding, then a response-bout analysis may be able to provide more information about the behavioral effects of drugs (Brackney et al., 2011; Johnson et al., 2011; but see Bennett, 2007, 2014).

Johnson et al. (2011) used methods described by Shull (2004) to examine effects of the drug pentobarbital on bout-initiation and within-bout rates in mice nose-poking for food under a 
second-order random-interval (RI) 60-s percentile (10:0.5) schedule of reinforcement. The random-interval schedule reinforced responses, on average, once per min. The percentile (10:0.5) schedule reinforced responses with IRTs that were shorter than $50 \%$ of the previous 10 IRTs. This schedule arrangement generated relatively high responses rates while holding reinforcement rate constant. Injections of small and intermediate doses of pentobarbital increased response rates while larger doses decreased response rates. Response rate increases were due primarily to an increase in bout-initiation rates while response rate decreases were due to decreases in both bout-initiation and within-bout rates. These results, which are consistent with past research showing that smaller doses of pentobarbital increased response rates while larger doses resulted in response suppression (Dews, 1955), indicate that motivational and motoric effects of certain drugs can be parsed using a response-bout analysis.

\section{Statement of the Problem}

The development of behavioral tolerance is correlated with how much reinforcement is obtained from behavior extraneous to the target behavior (i.e., the environmental context). For example, Dallery and Lancaster (1999) found that tolerance to the rate-decreasing effects of $d$ amphetamine developed to a greater extent in rats with more impoverished environmental contexts compared to rats with more enriched environmental contexts. In their study the environmental context was measured during baseline conditions and not directly manipulated. The exact role that the environmental context plays in the development of tolerance is therefore unknown. The present study was designed to address this problem by experimentally manipulating the environmental context to determine further how it affects the development of tolerance to the rate-decreasing effects of $d$-amphetamine in rats. Lever pressing for food pellets by rats was maintained under a multiple schedule consisting of two VI 60-s components. The 
environmental context in one component was enriched by providing non-contingent food pellets at a lower (VT 120-s schedule) or higher (VT 30-s schedule) rate for different groups of rats. Effects of $d$-amphetamine were assessed before (acute) and during (chronic) repeated administration of a dose of $d$-amphetamine that decreased the total number of food pellets earned by lever press. Based on findings reported by Dallery and Lancaster tolerance was expected to develop to a lesser extent in components with non-contingent food pellets compared to components without non-contingent food pellets. Tolerance was also expected to develop to a greater extent in components in which non-contingent food pellets were provided at a lower rate compared to components in which they were provided at a higher rate.

If responding does occur in bouts separated by relatively short pauses, with the bouts themselves being separated by relatively long pauses, then potentially important information about how tolerance develops could be obscured by examining only changes in response rates. That is, tolerance to the rate-decreasing effects of a drug could be due to changes in boutinitiation rates, within-bout rates, or some combination of both. Methods described by Shull (2004) were therefore used to examine effects of acute and chronic $d$-amphetamine administration on bout-initiation and within-bout rates in an effort to try and elucidate further the behavioral mechanisms governing the development of tolerance.

\section{Method}

\section{Subjects}

Twelve experimentally naïve male Sprague-Dawley rats (Harlan Sprague-Dawley, Inc. Indianapolis, IN) served as subjects. Rats were assigned randomly to a Less-Enriched Group (L1 - L6) or More-Enriched Group (M1 - M6) and housed individually in plastic cages under a 12-h reverse light-dark cycle in a colony room with temperature and humidity maintained at constant 
levels. Sessions were conducted during the dark phase at approximately the same time $( \pm 45$ min) each day. In home cages, rats had constant access to water and received 12-15 g of rat chow approximately $30 \mathrm{~min}$ after each session. This resulted in approximately $21 \mathrm{~h}$ of food restriction prior to the start of each session. These procedures were approved by the Animal Care and Use Committee of West Virginia University.

\section{Apparatus}

Sessions were conducted in eight rat operant-conditioning chambers, each enclosed in a sound-attenuating cubicle with a ventilation fan to circulate air and mask extraneous noise. Each chamber contained a work area of $30.5 \mathrm{~cm}$ by $24.5 \mathrm{~cm}$ by $21.0 \mathrm{~cm}$, a grid floor, a $45-\mathrm{mg}$ pellet dispenser, and a pellet receptacle centered between two retractable response levers, $11.5 \mathrm{~cm}$ apart from each other. Both levers were located $8 \mathrm{~cm}$ above the grid floor, protruded $1.9 \mathrm{~cm}$ into the chamber, were $4.8 \mathrm{~cm}$ wide, and required a press of $0.25 \mathrm{~N}$ for a response to be recorded. Each chamber contained two $28-\mathrm{V}$ lever lights, $2.5 \mathrm{~cm}$ in diameter, mounted approximately $7 \mathrm{~cm}$ above each lever, and a $28-\mathrm{V}$ houselight on the wall opposite the pellet dispenser. Presentation of each food pellet was accompanied by a houselight flash of $0.1 \mathrm{~s}$. Data collection and experimental events were controlled by MED-PC ${ }^{\mathrm{TM}}$ (Med Associates, VT) software and hardware interfaced to a personal computer.

\section{Lever-press Training}

Lever pressing was established by exposing rats to a conjoint FR 1 VT 60-s schedule of food delivery. These sessions began with extension of the left lever. A press on this lever resulted in the delivery of one food pellet. Independent of behavior, one food pellet was also provided, on average, every $60 \mathrm{~s}$. Sessions ended after 40 food pellets were presented. Lever pressing occurred reliably after three sessions for all rats. Rats were next exposed to an 
alternating FR 1 schedule of reinforcement. At the start of these sessions, one lever, randomly determined, was extended into the chamber. A press on this lever resulted in the delivery of one food pellet. After five consecutive lever presses, that lever was retracted. The other lever was then extended into the chamber and the same contingencies were in effect. The alternating FR 1 schedule remained in effect until 40 food pellets were delivered. Lever pressing on both levers occurred reliably after three to five sessions. Rats were next exposed to a two-component multiple schedule.

\section{Two-component Multiple Schedule}

One component of the two-component multiple schedule was signaled by extension of the left lever and illumination of the left lever light. The other component was signaled by extension of the right lever and illumination of the right lever light. The stimuli associated with each component were counterbalanced across rats in each group. Sessions were arranged into two blocks and each component was presented once per block. Thus, each component was presented twice per session. The order in which components were presented was fixed within and across sessions, and counterbalanced across subjects in each group. Components remained in effect until 10 food pellets were earned by lever press or 15 min elapsed. A 15 -min blackout preceded the start of each session and a 1-min blackout preceded presentation of subsequent components. During blackouts, both levers retracted and all lights were extinguished. Sessions were conducted seven days per week and lasted a maximum of $78 \mathrm{~min}$.

Throughout the experiment the value of the VI schedule was always the same in both components. Initially, this value was set at $1 \mathrm{~s}$. This resulted in one food pellet being delivered after the first lever press that occurred after an average of $1 \mathrm{~s}$. After four sessions, the value of the VI schedule was increased from $1 \mathrm{~s}$ to $20 \mathrm{~s}, 30 \mathrm{~s}, 40 \mathrm{~s}, 50 \mathrm{~s}$, and then $60 \mathrm{~s}$. Each value was in 
effect for four sessions before it was increased. This was done to minimize disruptions in lever pressing that could have occurred as reinforcement rate decreased.

\section{Baseline}

After four sessions in which the value of the VI schedule was $60 \mathrm{~s}$, non-contingent food pellets were provided in one component of the two-component multiple schedule under a VT 120-s schedule for rats in the Less-Enriched Group and under a VT 30-s schedule for rats in the More-Enriched Group. Technically, this resulted in the multiple schedule consisting of a VI 60-s component and a conjoint VI 60-s VT 120-s component for rats in the Less-Enriched Group, and a VI 60-s component and a conjoint VI 60-s VT 30-s component for rats in the More-Enriched Group. Because the order in which components were presented was fixed within session, the VT schedule was added to the first component presented for three rats in each group, and during the second component presented for the other three rats in each group. Pharmacological procedures began after lever pressing during baseline was stable.

Stability was assessed after 12 sessions and it was based on lever-press rates in each component, averaged across both blocks, from the last six sessions. Lever pressing was considered stable when lever-press rates varied $20 \%$ or less compared to the six-session average, and there was no upward or downward trend in lever-press rates based on visual inspection of daily graphs, or if 35 sessions had been conducted.

Programming of the VI and VT schedules was done as follows. For the VI schedules, one food pellet was delivered after the first lever press that occurred after a variable interval of time. For the VT schedules, one food pellet was provided independent of behavior after a variable interval of time. The first interval of time for the VI and VT schedules began at the start of the component in which those schedules were in effect. Subsequent intervals within a 
component were timed from the delivery of the previous food pellet. To provide a roughly constant probability of food pellet delivery after the delivery of the last food pellet, each interval was selected randomly without replacement from a list of values generated using methods described by Fleshler and Hoffman (1962). Separate timers were used for each schedule and they reset at the start of each component. Depending on the length of a component, the VT 120-s schedule was programmed to provide 5 to 8 additional food pellets while the VT 30-s schedule was programmed to provide 20 to 30 additional food pellets. Note, however, that the programmed rate of food pellet delivery differed from the obtained rate of food pellet delivery. During baseline, 5 food pellets were provided, on average, (range $1-8$ food pellets) by the VT 120-s schedule; 20 food pellets were provided, on average, (range $12-26$ food pellets) by the VT 30-s schedule.

\section{Pharmacological Regimen}

$d$-Amphetamine (Sigma-Aldrich, St. Louis, Missouri, USA) was dissolved in $0.9 \%$ sodium chloride $(1.0 \mathrm{mg} / \mathrm{ml})$ and injected (ip) at a volume of $1.0 \mathrm{ml} / \mathrm{kg}$ immediately prior to select experimental sessions. The doses of $d$-amphetamine tested ranged from 0.1 to $3.0 \mathrm{mg} / \mathrm{kg}$. Doses were injected in an ascending order, starting with saline. The number of injections of saline and each dose of $d$-amphetamine tested for rats in both groups are listed in Table 1.

Acute phase. Acute dose-effect functions were determined for each rat by injecting saline or a dose of $d$-amphetamine immediately prior to the start of select experimental sessions. Injections were separated by at least three days. Effects of saline and each dose of $d$ amphetamine were tested at least twice. Up to three additional injections of saline or a dose of $d$ amphetamine occurred if prior injections produced inconsistent effects. Systematic effects or trends across determinations of a particular dose were not observed within or across blocks. 
Table 1

The Number of Injections of Saline and Doses of d-Amphetamine Tested during the Acute and Chronic Phases for Rats in both Groups

\begin{tabular}{|c|c|c|c|c|c|c|c|c|c|c|c|c|}
\hline \multirow{2}{*}{ Group } & \multirow{2}{*}{ Subject } & \multirow{2}{*}{ Saline } & \multicolumn{10}{|c|}{$d$-Amphetamine $(\mathrm{mg} / \mathrm{kg})$} \\
\hline & & & 0.1 & 0.2 & 0.3 & 0.6 & 0.8 & 1.0 & 1.3 & 1.8 & 2.3 & 3.0 \\
\hline \multirow{6}{*}{$\begin{array}{l}\text { Less- } \\
\text { Enriched }\end{array}$} & L1 & $3(3)$ & $2(2)$ & - & $3(2)$ & $3(2)$ & - & $4(2)$ & - & $2(14)^{*}$ & - & $2(2)$ \\
\hline & L2 & $3(3)$ & $3(2)$ & - & $2(2)$ & - & - & $3(2)$ & - & $4(11)^{*}$ & - & $2(2)$ \\
\hline & L3 & $4(3)$ & $3(2)$ & - & $2(2)$ & $2(2)$ & - & $3(2)$ & - & $4(2)$ & $4(15)^{*}$ & $2(2)$ \\
\hline & L4 & $4(2)$ & $3(3)$ & - & $2(3)$ & - & - & $3(2)$ & $3(2)$ & $3(2)$ & $2(16)^{*}$ & $2(2)$ \\
\hline & L5 & $4(2)$ & $4(2)$ & - & $3(2)$ & - & - & $2(2)$ & - & $3(2)$ & $4(12)^{*}$ & $3(2)$ \\
\hline & L6 & $4(3)$ & $3(3)$ & - & $2(2)$ & - & - & $3(2)$ & - & $3(12)^{*}$ & - & $3(2)$ \\
\hline \multirow{6}{*}{$\begin{array}{l}\text { More- } \\
\text { Enriched }\end{array}$} & M1 & $4(4)$ & $2(2)$ & - & $3(2)$ & $2(2)$ & - & $2(2)$ & $2(2)$ & $3(17)^{*}$ & - & $2(3)$ \\
\hline & M2 & $4(3)$ & $3(3)$ & - & $2(3)$ & $3(3)$ & - & $2(3)$ & - & $3(17)^{*}$ & - & $2(2)$ \\
\hline & M3 & $3(3)$ & - & - & $2(3)$ & - & - & $2(3)$ & - & $2(2)$ & - & $2(11)^{*}$ \\
\hline & M4 & $4(2)$ & $3(2)$ & - & $3(2)$ & $4(2)$ & - & $\begin{array}{l}5 \\
(10)^{*}\end{array}$ & - & $3(2)$ & - & - \\
\hline & M5 & $3(2)$ & $3(2)$ & $2(2)$ & $3(2)$ & $3(2)$ & $2(13)^{*}$ & $3(3)$ & - & - & - & - \\
\hline & M6 & $3(4)$ & $2(2)$ & - & $3(2)$ & $2(2)$ & - & $4(3)$ & $318)^{*}$ & $3(3)$ & - & $2(2)$ \\
\hline
\end{tabular}

Note. Values to the left of the parentheses refer to the number of injections during the acute phase. Values inside the parentheses refer to the number of injections during the chronic phase. The individually selected repeated dose is indicated by the asterisk $(*)$; data for those doses were collected on the days immediately before probe sessions during the chronic phase hence there are more determinations for these doses than others. Dashes indicate doses that were not tested.

Repeated phase. After an acute dose-effect function was obtained, saline was injected, once daily, immediately prior to experimental sessions for four days. This was done to expose rats to the repeated (i.e., daily) injection regime and test for possible disruptions in lever pressing due to repeated injections. Lever-press rates during these four sessions were similar to leverpress rates when saline was injected acutely. Then, immediately prior to the start of each experimental session, an individually selected dose of $d$-amphetamine was injected. This repeatedly injected dose of $d$-amphetamine was determined for each rat based on its' acute doseeffect function. The dose selected was the smallest dose that reduced the total number of food pellets earned by lever press during sessions by at least $50 \%$ compared to when saline was injected acutely. Recall that a maximum of 40 food pellets could be could be earned by lever press during a session. The repeatedly injected dose of $d$-amphetamine was $0.8 \mathrm{mg} / \mathrm{kg}$ for rat $\mathrm{M} 5,1.0 \mathrm{mg} / \mathrm{kg}$ for rat M4, $1.3 \mathrm{mg} / \mathrm{kg}$ for rat M6, $1.8 \mathrm{mg} / \mathrm{kg}$ for rats M1, M2, L1, L2, and L6, 2.3 
$\mathrm{mg} / \mathrm{kg}$ for rats $\mathrm{L} 3, \mathrm{~L} 4$, and $\mathrm{L} 5$, and $3.0 \mathrm{mg} / \mathrm{kg}$ for rat M3. Individually selected doses of $d$ amphetamine were injected once daily, pre-session, for 45 days. Next, chronic effects of $d$ amphetamine were assessed.

Chronic phase. Chronic dose-effect functions were determined in the context of continued repeated injections of $d$-amphetamine. The repeated dose of $d$-amphetamine was still injected immediately prior to the start of each session, except during probe sessions. During probe sessions, the repeated dose of $d$-amphetamine was substituted with saline or a dose of $d$ amphetamine that was tested during the acute phase. Probe sessions were separated by at least three days, and on intervening days the repeated dose of $d$-amphetamine was injected. Effects of saline and $d$-amphetamine were tested at least twice in an ascending order, starting with saline. Up to three additional injections of saline or a dose of $d$-amphetamine occurred if prior injections produced inconsistent effects. Systematic effects or trends across determinations of a particular dose were not observed within or across blocks.

Additional manipulations. During the acute phase for rat M3, lever-press rates following injections of saline and $d$-amphetamine varied substantially. These inconsistent effects may have been related to the variability in lever-press rates during sessions between injections as indicated by visual inspection of daily graphs. In an attempt to reduce the variability in leverpress rates, and obtain more consistent effects of saline and $d$-amphetamine, a one-week washout was implemented during which no injections occurred. Lever-press rates during the washout period were less variable compared to before the washout period. Acute effects of saline and $d$ amphetamine were therefore re-determined following the one-week washout. For this redetermination, doses were injected in a descending order starting with $3.0 \mathrm{mg} / \mathrm{kg} d$-amphetamine because prior injections of that dose did not decrease the number of food pellets earned by lever 
press, and it was unclear if a dose larger than $3.0 \mathrm{mg} / \mathrm{kg}$ needed to be tested. Data from the redetermined, not the initial, acute dose-effect function are reported for this rat.

During the first six days of the repeated phase for rat L1, effects of $1.0 \mathrm{mg} / \mathrm{kg} d$ amphetamine, which was the repeated dose originally selected for this rat, were inconsistent compared to the acute effects of this dose. Specifically, there was a minimal decrease in the number of food pellets earned during the first six days of the repeated phase. Because little, if any, reinforcement loss (i.e., decrease in the number of food pellets earned by lever press) occurred, the repeated dose for this rat was increased to $1.8 \mathrm{mg} / \mathrm{kg} d$-amphetamine, which was the next largest dose tested during the acute phase. To keep the length of the repeated phase consistent for all rats, $1.8 \mathrm{mg} / \mathrm{kg}$ was repeatedly injected once daily, prior to each session, for 39 days.

\section{Data Analysis}

Lever-press rates were calculated by dividing the total number of lever presses that occurred in each component by the time spent in that component and expressed as lever presses/min. There were no consistent differences in lever-press rates between components with the same schedule across the two blocks of a session. Lever-press rates were therefore averaged across components with the same schedules to describe behavior and drug effects more clearly. For the acute and chronic dose-effect functions, average lever-press rates for both components from the sessions in which doses of $d$-amphetamine were tested were expressed as the percent of lever-press rates from sessions in which saline was tested.

The time when each lever press occurred during each component was also measured and used to construct log-survivor functions. These inter-response times (IRTs) were organized into 0.1-s bins, and the proportion of IRTs longer than each bin size was plotted (on a log scale) as a 
function of bin size. Log-survivor functions were constructed for each component for every session for each rat. Visual inspection of these log-survivor functions did not reveal consistent differences between components with the same schedule across the two blocks of a session. IRTs for each component were therefore collapsed across components with the same schedules. To reduce the influence that outlying IRTs from any particular session had on bout-initiation and within-bout rate estimates and improve clarity, IRTs were also collapsed across sessions for each phase. For the baseline condition, IRTs were collapsed across the last six stable baseline sessions. For the acute and chronic phases, IRTs were collapsed across sessions in which saline or a particular dose of $d$-amphetamine was tested.

The regression wizard in SigmaPlot $\subset$ 10.0 was used to quantify bout-initiation and within-bout rates by fitting a double-exponential function with four parameters (see above) and reciprocal- $y$ weighting to the survivor functions. Shull and Grimes (2003) found that reciprocal$y$ weighting improved fits of the equation to their data and produced parameter estimates similar to those produced when the weighting was not used. As an added constraint, $p+(1-p)$ was set equal to 1 . This resulted in all responses being classified as bout-initiation or within-bout responses. Through an iterative process, the regression wizard determined the parameters that minimized the sum of the squared deviations. For all regressions, the goodness of fit was assessed using obtained $r^{2}$ values.

The extent to which tolerance developed was determined by comparing the area under the curve (AUC) of the acute and chronic dose-effect functions for each rat. The AUC is the area under the plotted values (i.e., lever-press rates) bound by the section on the $x$-axis on which the independent variable (i.e., doses of $d$-amphetamine tested) is plotted. To account for differences in the range of doses tested between rats, the doses injected were expressed as a proportion of the 
largest dose tested for each rat. To account for differences in lever-press rates between rats and components for the acute and chronic phases, lever-press rates were expressed as a proportion of average lever-press rates obtained when saline was tested for each rat. Calculating AUC in this manner allowed drug effects to be compared between components for rats in both groups (Macaskill and Branch, 2012; Minervini and Branch, 2013). A tolerance ratio (Hughes et al., 2005) was then calculated for each rat to quantify the extent to which tolerance developed. This was done by dividing the AUC of the chronic dose-effect function by the AUC of the acute doseeffect function. Values greater than 1.0 indicate that tolerance developed.

\section{Results}

\section{Response-rate Analysis}

Baseline. Figure 2 shows lever-press rates averaged across the last six stable baseline sessions for both components of the multiple schedule for rats in both groups. These data are also listed in Table 2. Lever-press rates varied across rats in each group and were not systematically related to component or group. For both groups, lever-press rates were higher for some rats in components with non-contingent food pellets (open or grey-filled bars) compared to components without non-contingent food pellets (closed bars). For other rats, there was little difference, or the opposite occurred. A repeated-measure ANOVA with component as a withinsubject factor and group as a between-subject factor indicated that there was no statistically significant group by component interaction $[F(1,10)=.001, p>.05]$ or main effect of component $[F(1,10)=1.19, p>.05]$ on lever-press rates. There was also no statistically significant difference in the number of sessions it took to meet stability criteria for rats in the Less-Enriched Group $(M=19, S E M=4)$ compared to rats in the More-Enriched Group $(M=27$, $S E M=4), t(10)=1.6, p>.05$. 
Rats in both groups earned the maximum number of food pellets possible (i.e., 10) in components with and without non-contingent food pellets. In components with non-contingent food pellets, rats in the Less-Enriched Group were provided, on average, 5 additional food pellets (range 1 to 8), while rats in the More-Enriched Group were provided, on average, 20 additional food pellets (range 12 to 26). Additional food pellets were not provided in components without non-contingent food pellets. These data indicate that components with noncontingent food pellets were enriched to a greater extent for rats in the More-Enriched Group compared to the Low-Enriched Group, and that components with non-contingent food pellets were enriched to a greater extent compared to components without non-contingent food pellets for rats in both groups.

Less-Enriched Group

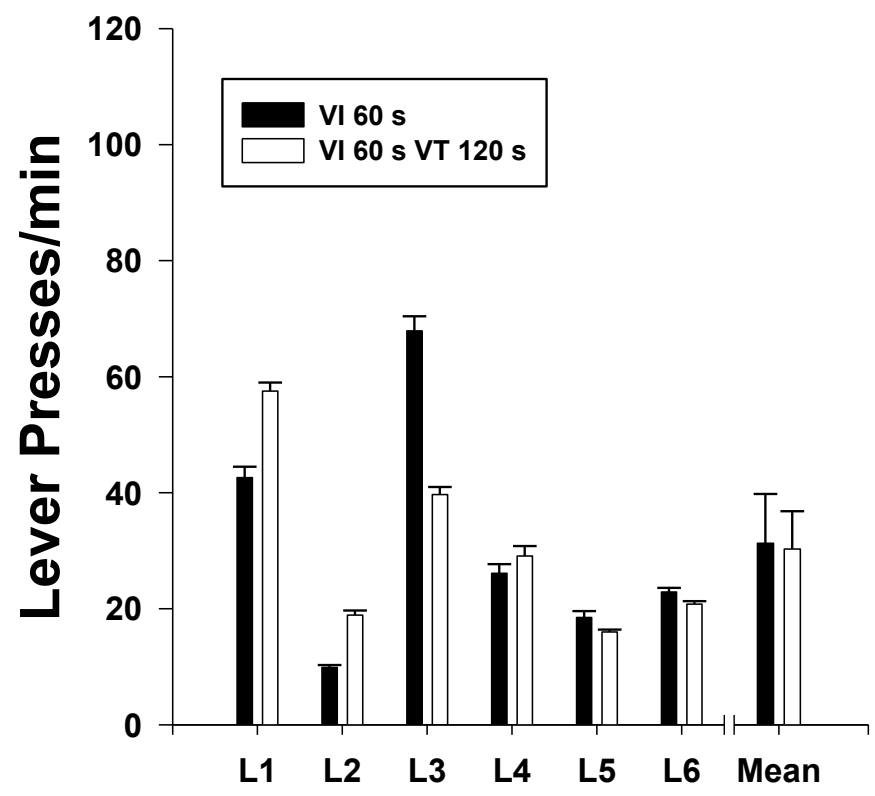

More-Enriched Group

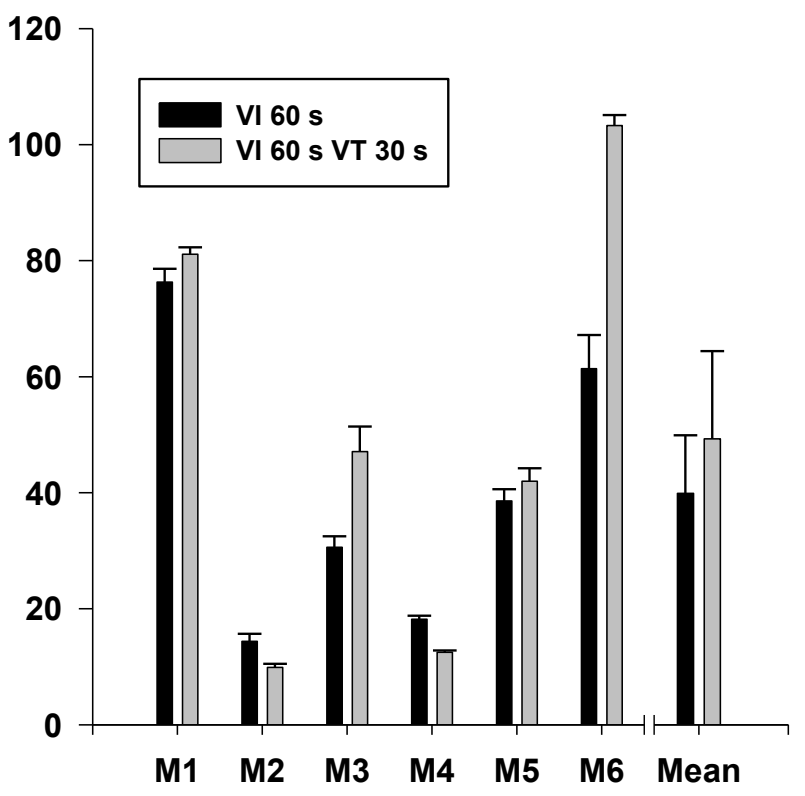

\section{Subject}

Figure 2. Lever presses/min averaged across the last six stable baseline sessions for both components of the multiple schedule for rats in both groups. Lever presses in components without non-contingent food pellets are depicted by the closed bars. Lever presses in components with non-contingent food pellets are depicted by the open bars for rats in the LessEnriched Group, and by the grey bars for rats in the More-Enriched Group. Error bars represent \pm 1 SEM. 
Table 2

Lever-Presses/min ( \pm 1 SEM) averaged across the Last Six Stable Baseline Sessions for the Multiple Schedule Components for Rats in both Groups

\begin{tabular}{llccc}
\cline { 3 - 5 } Group & Subject & \multicolumn{3}{c}{ Component } \\
\cline { 3 - 5 } Less- & L1 & VI 60 s & VI 60 s VT 120 s & VI 60 s VT 30 s \\
Enriched & L2 & $10(1)$ & $58(2)$ & - \\
& L3 & $68(3)$ & $19(1)$ & - \\
& L4 & $26(2)$ & $40(1)$ & - \\
& L5 & $19(1)$ & $29(2)$ & - \\
& L6 & $23(1)$ & $21(1)$ & - \\
More- & M1 & $76(2)$ & - & $81(1)$ \\
Enriched & M2 & $14(1)$ & - & $10(1)$ \\
& M3 & $31(2)$ & - & $47(4)$ \\
& M4 & $18(1)$ & - & $42(1)$ \\
& M5 & $39(2)$ & - & $103(2)$ \\
\hline
\end{tabular}

Note. Rats in the Less-Enriched Group were not exposed to the VI 60-s VT 30 -s component; rats in the More-Enriched Group were not exposed to the VI 60-s VT 120-s component.

Acute and chronic phases. Acute injections of $d$-amphetamine (open symbols) dosedependently decreased lever-press rates in both components of the multiple schedule as shown in Figure 3 for rats in the Less-Enriched Group and Figure 4 for rats in the More-Enriched Group. Consistent differences in the rate-decreasing effect of $d$-amphetamine between components were not evident, and sensitivity to dose varied between subjects. Inspection of Figures 3 and 4 shows that $d$-amphetamine decreased lever-press rates to a greater extent for some rats in both groups in components with non-contingent food pellets compared to components without non-contingent food pellets. For other rats, there was little difference, or the opposite effect occurred. Smaller doses of $d$-amphetamine also suppressed lever-press rates to a greater extent for some rats (i.e., rat M5), whereas larger doses were needed to suppress lever-press rates for other rats (i.e., rat 
M3). For all rats in both groups, however, relatively large doses were required to decrease the number of food pellets earned by lever press. The extent to which $d$-amphetamine suppressed lever-press rates (i.e., acute AUC) was not systematically related to lever-press rates during baseline for rats in either group in components with non-contingent food pellets [Less-Enriched Group, $r(4)=-.53, p>.05$; More-Enriched Group, $r(4)=-.70, p>.05]$ or in components without non-contingent food pellets [Less-Enriched Group, $r(4)=-.63, p>.05$; More-Enriched Group, $r(4)=-.30, p>.05]$. Mean lever-press rates when saline and each dose of $d$-amphetamine were tested are listed in Table 3 for rats in the Less-Enriched Group and Table 4 for rats in the MoreEnriched Group. AUCs for rats in both groups are listed in Table 5.

Inspection of Figures 3 and 4 reveals that tolerance developed to the rate-decreasing effect of $d$-amphetamine in both components of the multiple schedule for rats in both groups, except for rat L4 (see Figure 3). This is evidenced by the rightward, and in some cases, upward, shift of the chronic dose-effect function (closed symbols) compared to the acute dose-effect function (open symbols). For rat L4, however, the chronic dose-effect function shifted to the left of the acute dose-effect function in the component without non-contingent food pellets, and was nearly identical to the acute dose-effect function in the component with non-contingent food pellets. The leftward shift of the chronic dose-effect function indicates that lever-press rates were more sensitive to effects of $d$-amphetamine, while the nearly identical function indicates no change. 


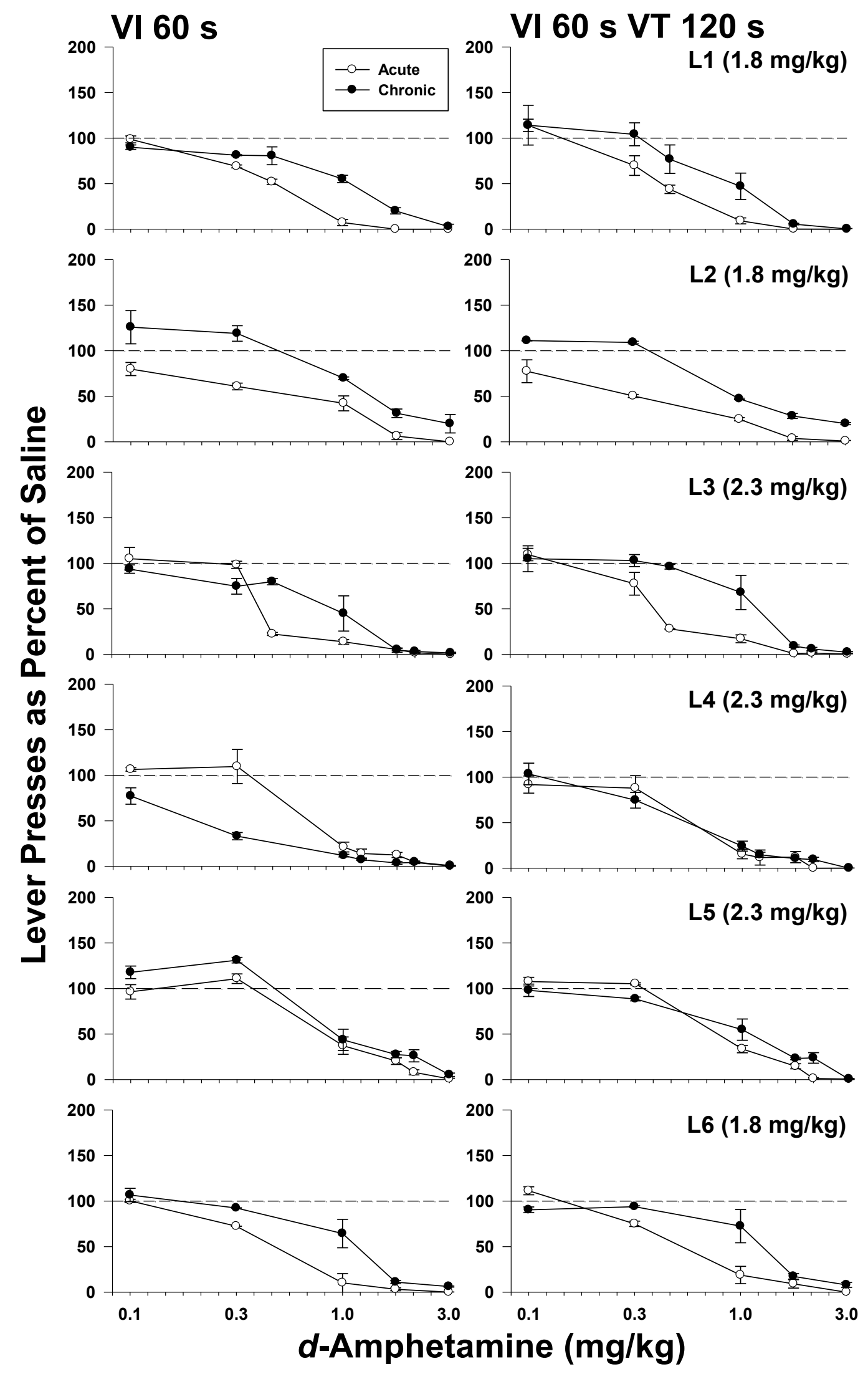


Figure 3. Dose-effect functions across components (columns) for each rat (rows) in the LessEnriched Group. Lever-press rates are expressed as percent of lever-press rates from sessions in which saline was injected. The repeated dose of $d$-amphetamine is indicated in parenthesis next to rat identification. Data from the acute phase are indicated by open circles; closed circles represent data from the chronic phase. Error bars represent \pm 1 SEM. Dashed horizontal lines indicate no change from when saline was injected. During the chronic phase, data for the repeated dose were taken from sessions the day before probe sessions; hence more determinations for the repeated dose are included in the mean than for other doses. 


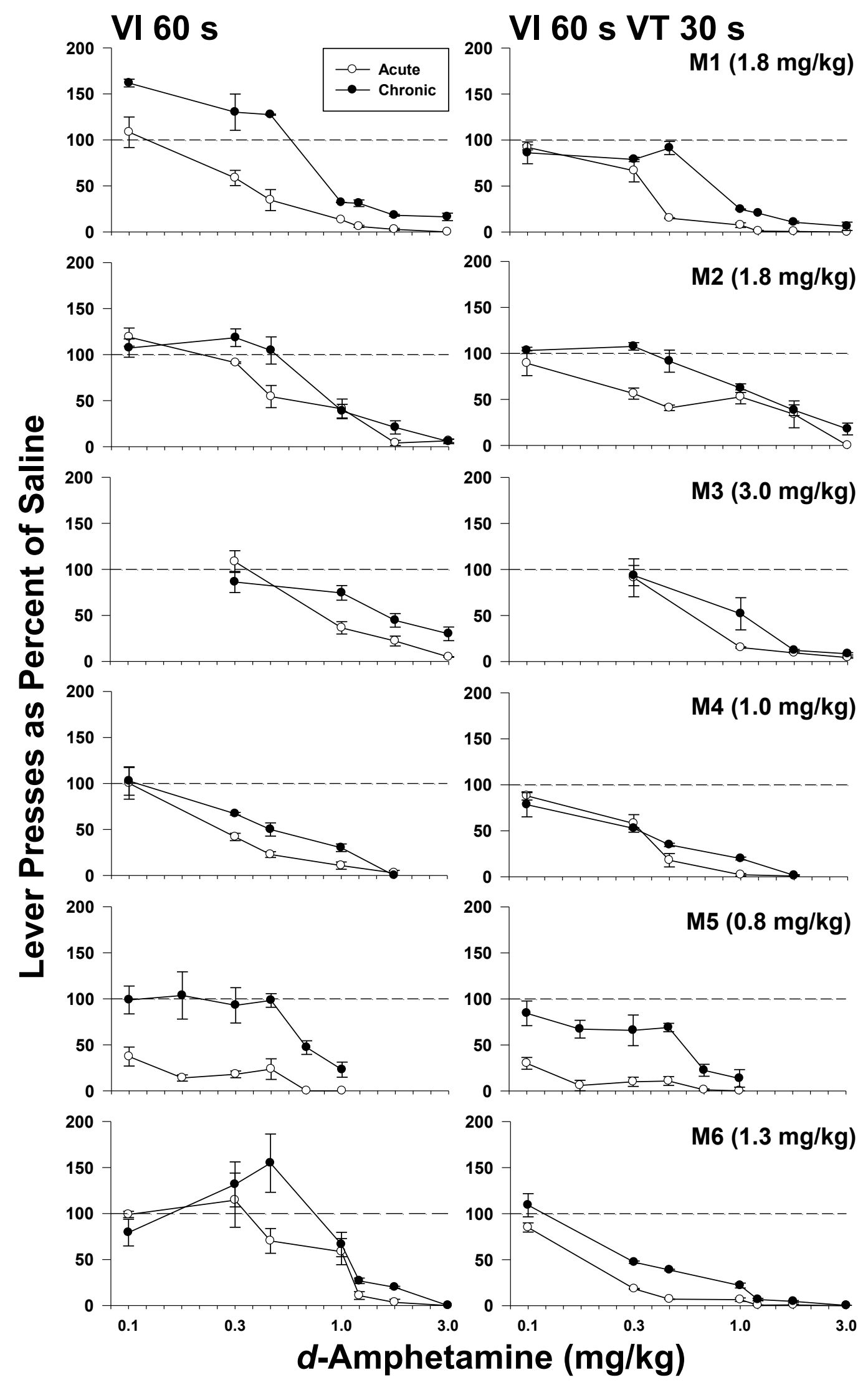


Figure 4. Dose-effect functions across components (column) for each rat (rows) in the MoreEnriched Group. Lever-press rates are expressed as percent of lever-press rates from sessions in which saline was injected. The repeated dose of $d$-amphetamine is indicated in parenthesis next to rat identification. Data from the acute phase are indicated by open circles; closed circles represent data from the chronic phase. Error bars represent \pm 1 SEM. Dashed horizontal lines indicate no change from saline injections. During the chronic phase, data for the repeated dose were taken from sessions the day before probe sessions; hence more determinations for the repeated dose are included in the mean than for other doses. 


\section{Less-Enriched Group}

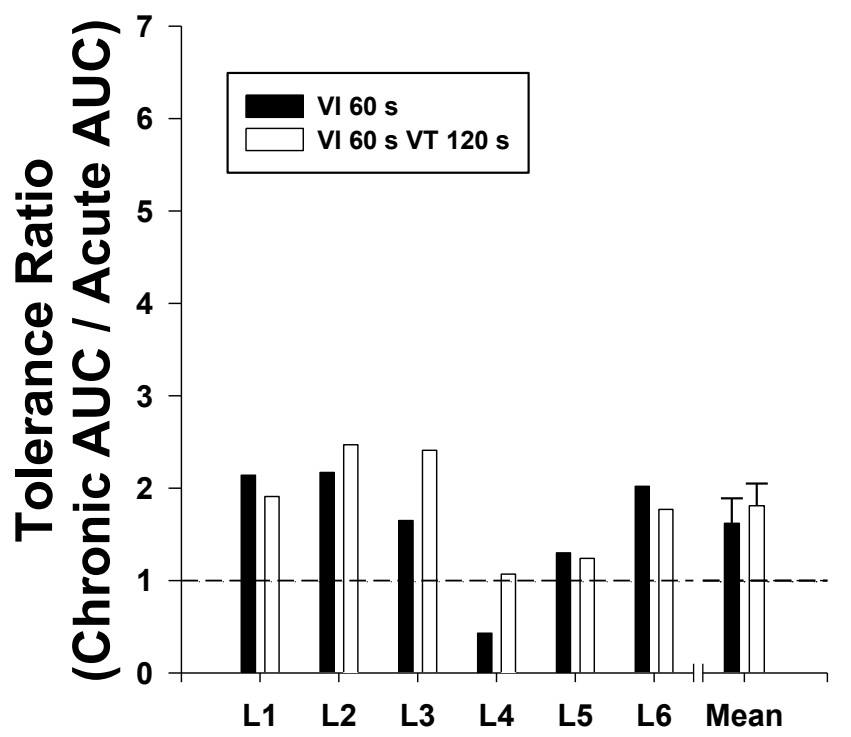

\section{More-Enriched Group}

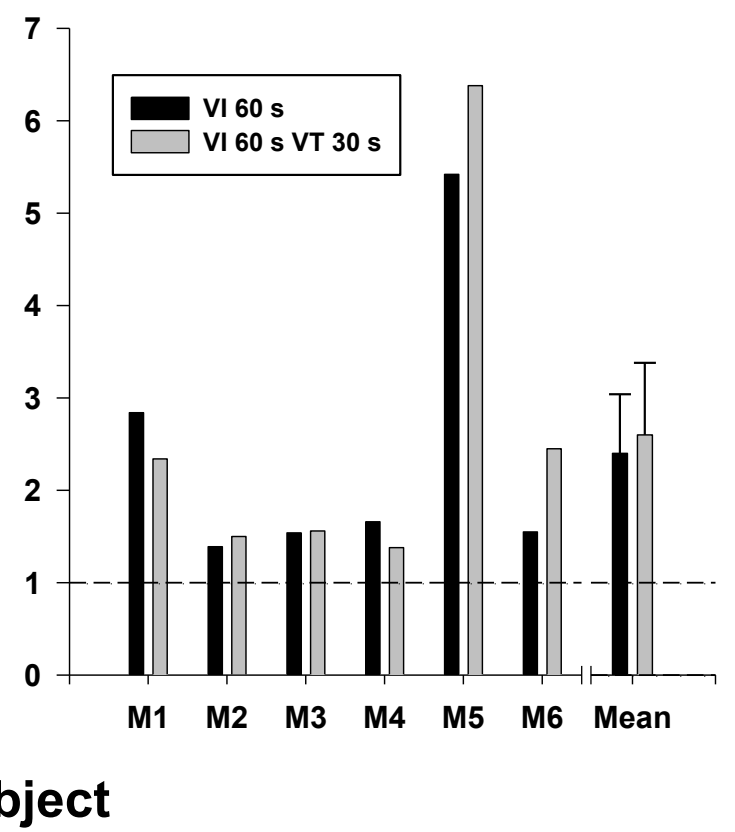

Figure 5. The ratio between the area under the curve (AUC) of the dose-effect function from the chronic phase and the acute phase for rats in both groups. Ratios for components without noncontingent food pellets are depicted by the closed bars; ratios for components with noncontingent food pellets are depicted by the open bars for rats in the Less-Enriched Group and by the grey bars for rats in the More-Enriched Group. The dashed line at 1.0 represents no change in AUC values from the acute phase. Error bars represent \pm 1 SEM. 
Table 3

Lever Presses/min ( \pm 1 SEM) averaged across Sessions in which Saline and d-Amphetamine were Tested during the Acute and Chronic Phases for the Multiple Schedule Components for Rats in the Less-Enriched Group

\begin{tabular}{|c|c|c|c|c|c|}
\hline \multirow{3}{*}{ Subject } & \multirow{3}{*}{ Dose (mg/kg) } & \multicolumn{4}{|c|}{ Component } \\
\hline & & \multicolumn{2}{|c|}{ VI $60 \mathrm{~s}$} & \multicolumn{2}{|c|}{ VI $60 \mathrm{~s} \mathrm{VT} 120 \mathrm{~s}$} \\
\hline & & Acute & Chronic & Acute & Chronic \\
\hline \multirow[t]{7}{*}{ L1 } & Saline & $24(2)$ & $20(2)$ & $35(3)$ & $26(3)$ \\
\hline & 0.1 & $24(1)$ & $18(1)$ & $40(2)$ & $30(6)$ \\
\hline & 0.3 & $16(0)$ & $16(0)$ & $25(4)$ & $28(3)$ \\
\hline & 0.6 & $12(1)$ & $16(2)$ & $16(2)$ & $20(4)$ \\
\hline & 1.0 & $2(1)$ & $11(1)$ & $3(1)$ & $12(4)$ \\
\hline & 1.8 & $0(0)$ & $4(1)$ & $0(0)$ & $2(0)$ \\
\hline & 3.0 & $0(0)$ & $1(0)$ & $0(0)$ & $0(0)$ \\
\hline \multirow[t]{6}{*}{$\mathrm{L} 2$} & Saline & $8(0)$ & $11(1)$ & $18(1)$ & $17(1)$ \\
\hline & 0.1 & $7(1)$ & $13(2)$ & $14(2)$ & $19(0)$ \\
\hline & 0.3 & $5(0)$ & $13(1)$ & $9(0)$ & $19(0)$ \\
\hline & 1.0 & $4(1)$ & $8(0)$ & $5(0)$ & $8(0)$ \\
\hline & 1.8 & $1(0)$ & $3(1)$ & $1(0)$ & $5(1)$ \\
\hline & 3.0 & $0(0)$ & $2(1)$ & $0(0)$ & $3(0)$ \\
\hline \multirow[t]{8}{*}{ L3 } & Saline & $41(3)$ & $40(5)$ & $33(4)$ & $25(3)$ \\
\hline & 0.1 & $43(5)$ & $37(2)$ & $36(2)$ & $26(4)$ \\
\hline & 0.3 & $40(2)$ & $30(3)$ & $26(4)$ & $25(2)$ \\
\hline & 0.6 & $9(1)$ & $32(1)$ & $9(0)$ & $24(1)$ \\
\hline & 1.0 & $6(1)$ & $18(8)$ & $6(1)$ & $17(5)$ \\
\hline & 1.8 & $2.2(1)$ & $8(3)$ & $0(0)$ & $8(3)$ \\
\hline & 2.3 & $1(0)$ & $1(1)$ & $1(0)$ & $2(1)$ \\
\hline & 3.0 & $0(0)$ & $1(0)$ & $0(0)$ & $0(0)$ \\
\hline \multirow[t]{8}{*}{ L4 } & Saline & $16(2)$ & $38(3)$ & $16(1)$ & $33(2)$ \\
\hline & 0.1 & $17(0)$ & $30(3)$ & $15(2)$ & $35(4)$ \\
\hline & 0.3 & $18(3)$ & $13(2)$ & $14(2)$ & $25(3)$ \\
\hline & 1.0 & $3(1)$ & $5(1)$ & $3(1)$ & $8(2)$ \\
\hline & 1.3 & $2(1)$ & $3(0)$ & $2(1)$ & $5(1)$ \\
\hline & 1.8 & $2(0)$ & $1(1)$ & $2(1)$ & $4(0)$ \\
\hline & 2.3 & $1(0)$ & $2(1)$ & $0(0)$ & $3(1)$ \\
\hline & 3.0 & $0(0)$ & $0(0)$ & $0(0)$ & $0(0)$ \\
\hline
\end{tabular}


Table 3 continued

Table 3 continued

\begin{tabular}{|c|c|c|c|c|c|}
\hline \multirow{3}{*}{ Subject } & \multirow{3}{*}{ Dose $(\mathrm{mg} / \mathrm{kg})$} & \multicolumn{4}{|c|}{ Component } \\
\hline & & \multicolumn{2}{|c|}{ VI $60 \mathrm{~s}$} & \multicolumn{2}{|c|}{ VI $60 \mathrm{~s} \mathrm{VT} 120 \mathrm{~s}$} \\
\hline & & Acute & Chronic & Acute & Chronic \\
\hline \multirow[t]{7}{*}{ L5 } & Saline & $15(1)$ & $17(1)$ & $19(1)$ & $21(1)$ \\
\hline & 0.1 & $15(1)$ & $20(1)$ & $21(1)$ & $20(1)$ \\
\hline & 0.3 & $17(1)$ & $22(1)$ & $20(0)$ & $18(0)$ \\
\hline & 1.0 & $6(2)$ & $7(2)$ & $7(1)$ & $11(2)$ \\
\hline & 1.8 & $3(1)$ & $5(1)$ & $3(0)$ & $5(0)$ \\
\hline & 2.3 & $1(0)$ & $4(1)$ & $0(0)$ & $5(1)$ \\
\hline & 3.0 & $0(0)$ & $1(0)$ & $0(0)$ & $0(0)$ \\
\hline \multirow[t]{6}{*}{ L6 } & Saline & $30(2)$ & $26(4)$ & $24(2)$ & $26(1)$ \\
\hline & 0.1 & $30(1)$ & $28(2)$ & $26(1)$ & $23(1)$ \\
\hline & 0.3 & $22(0)$ & $24(0)$ & $18(1)$ & $24(0)$ \\
\hline & 1.0 & $3(3)$ & $17(4)$ & $4(2)$ & $19(5)$ \\
\hline & 1.8 & $1(1)$ & $3(0)$ & $2(1)$ & $5(1)$ \\
\hline & 3.0 & $0(0)$ & $2(0)$ & $0(0)$ & $2(1)$ \\
\hline
\end{tabular}


Table 4

Lever Presses/min $( \pm 1$ SEM) averaged across Sessions in which Saline and d-Amphetamine were Tested during the Acute and Chronic Phases for the Multiple Schedule Components for Rats in the More-Enriched Group

\begin{tabular}{|c|c|c|c|c|c|}
\hline \multirow{3}{*}{ Subject } & \multirow{3}{*}{ Dose (mg/kg) } & \multicolumn{4}{|c|}{ Component } \\
\hline & & \multicolumn{2}{|c|}{ VI $60 \mathrm{~s}$} & \multicolumn{2}{|c|}{ VI $60 \mathrm{~s} \mathrm{VT} 30 \mathrm{~s}$} \\
\hline & & Acute & Chronic & Acute & Chronic \\
\hline \multirow[t]{8}{*}{ M1 } & Saline & $51(6)$ & $34(3)$ & $59(4)$ & $51(4)$ \\
\hline & 0.1 & $55(8)$ & $55(1)$ & $55(2)$ & $44(6)$ \\
\hline & 0.3 & $30(4)$ & $45(7)$ & $40(7)$ & $40(1)$ \\
\hline & 0.6 & $18(6)$ & $44(0)$ & $9(0)$ & $46(4)$ \\
\hline & 1.0 & $7(0)$ & $11(0)$ & $5(2)$ & $13(0)$ \\
\hline & 1.3 & $3(1)$ & $11(1)$ & $1(0)$ & $10(0)$ \\
\hline & 1.8 & $1(1)$ & $6(0)$ & $0(0)$ & $5(1)$ \\
\hline & 3.0 & $0(0)$ & $6(1)$ & $0(0)$ & $3(2)$ \\
\hline \multirow[t]{7}{*}{ M2 } & Saline & $8(2)$ & $11(1)$ & $7(1)$ & $11(0)$ \\
\hline & 0.1 & $9(1)$ & $11(1)$ & $7(1)$ & $11(0)$ \\
\hline & 0.3 & $7(0)$ & $12(1)$ & $4(1)$ & $12(0)$ \\
\hline & 0.6 & $4(1)$ & $11(2)$ & $3(0)$ & $10(1)$ \\
\hline & 1.0 & $3(1)$ & $4(1)$ & $4(1)$ & $7(1)$ \\
\hline & 1.8 & $0(0)$ & $2(1)$ & $3(1)$ & $4(1)$ \\
\hline & 3.0 & $1(0)$ & $1(0)$ & $0(0)$ & $2(1)$ \\
\hline \multirow[t]{5}{*}{ M3 } & Saline & $30(5)$ & $28(3)$ & $51(4)$ & $59(8)$ \\
\hline & 0.3 & $32(4)$ & $24(3)$ & $46(11)$ & $55(6)$ \\
\hline & 1.0 & $11(2)$ & $21(2)$ & $8(0)$ & $30(10)$ \\
\hline & 1.8 & $7(2)$ & $12(2)$ & $5(0)$ & $7(1)$ \\
\hline & 3.0 & $1(0)$ & $8(2)$ & $2(0)$ & $5(1)$ \\
\hline \multirow[t]{6}{*}{ M4 } & Saline & $15(2)$ & $11(2)$ & $13(1)$ & $18(3)$ \\
\hline & 0.1 & $15(3)$ & $12(2)$ & $11(1)$ & $14(2)$ \\
\hline & 0.3 & $6(1)$ & $8(0)$ & $8(1)$ & $9(0)$ \\
\hline & 0.6 & $4(1)$ & $6(1)$ & $2(1)$ & $6(0)$ \\
\hline & 1.0 & $2(1)$ & $3(1)$ & $0(0)$ & $4(0)$ \\
\hline & 1.8 & $0(0)$ & $0(0)$ & $0(0)$ & $0(0)$ \\
\hline
\end{tabular}


Table 4 continued

\begin{tabular}{|c|c|c|c|c|c|}
\hline \multirow{3}{*}{ Subject } & \multirow{3}{*}{ Dose $(\mathrm{mg} / \mathrm{kg})$} & \multicolumn{4}{|c|}{ Component } \\
\hline & & \multicolumn{2}{|c|}{ VI $60 \mathrm{~s}$} & \multicolumn{2}{|c|}{ VI $60 \mathrm{~s} \mathrm{VT} 30 \mathrm{~s}$} \\
\hline & & Acute & Chronic & Acute & Chronic \\
\hline \multirow[t]{7}{*}{ M5 } & Saline & $12(1)$ & $15(2)$ & $20(2)$ & $24(1)$ \\
\hline & 0.1 & $5(1)$ & $15(2)$ & $6(1)$ & $21(3)$ \\
\hline & 0.2 & $2(0)$ & $15(4)$ & $1(1)$ & $16(2)$ \\
\hline & 0.3 & $2(0)$ & $14(3)$ & $2(1)$ & $16(4)$ \\
\hline & 0.6 & $3(1)$ & $14(1)$ & $2(1)$ & $17(1)$ \\
\hline & 0.8 & $0(0)$ & $7(1)$ & $0(0)$ & $5(2)$ \\
\hline & 1.0 & $0(0)$ & $3(1)$ & $0(0)$ & $3(2)$ \\
\hline \multirow[t]{8}{*}{ M6 } & Saline & $8(1)$ & $10(2)$ & $54(4)$ & $40(2)$ \\
\hline & 0.1 & $8(0)$ & $8(1)$ & $46(3)$ & $44(5)$ \\
\hline & 0.3 & $10(2)$ & $13(2)$ & $10(0)$ & $19(1)$ \\
\hline & 0.6 & $6(1)$ & $15(3)$ & $4(0)$ & $16(0)$ \\
\hline & 1.0 & $5(1)$ & $6(1)$ & $4(1)$ & $9(1)$ \\
\hline & 1.3 & $1(0)$ & $3(0)$ & $0(0)$ & $3(1)$ \\
\hline & 1.8 & $0(0)$ & $2(0)$ & $1(0)$ & $2(0)$ \\
\hline & 3.0 & $0(0)$ & $0(0)$ & $0(0)$ & $0(0)$ \\
\hline
\end{tabular}


Table 5

Area Under the Curve of the Dose-Effect Functions for the Acute and Chronic Phases for the Multiple Schedule Components for Rats in both Groups

\begin{tabular}{|c|c|c|c|c|c|c|c|}
\hline \multirow{3}{*}{ Group } & \multirow{3}{*}{ Subject } & \multicolumn{6}{|c|}{ Component } \\
\hline & & \multicolumn{2}{|c|}{ VI $60 \mathrm{~s}$} & \multicolumn{2}{|c|}{ VI $60 \mathrm{~s}$ VT $120 \mathrm{~s}$} & \multicolumn{2}{|c|}{ VI $60 \mathrm{~s}$ VT $30 \mathrm{~s}$} \\
\hline & & Acute & Chronic & Acute & Chronic & Acute & Chronic \\
\hline \multirow{6}{*}{$\begin{array}{l}\text { Less- } \\
\text { Enriched }\end{array}$} & L1 & 0.19 & 0.40 & 0.19 & 0.36 & - & - \\
\hline & L2 & 0.27 & 0.58 & 0.20 & 0.49 & - & - \\
\hline & L3 & 0.21 & 0.35 & 0.20 & 0.48 & - & - \\
\hline & L4 & 0.32 & 0.14 & 0.25 & 0.27 & - & - \\
\hline & L5 & 0.39 & 0.50 & 0.35 & 0.43 & - & - \\
\hline & L6 & 0.21 & 0.42 & 0.26 & 0.46 & - & - \\
\hline \multirow{6}{*}{$\begin{array}{l}\text { More- } \\
\text { Enriched }\end{array}$} & M1 & 0.18 & 0.52 & - & - & 0.14 & 0.32 \\
\hline & M2 & 0.32 & 0.45 & - & - & 0.37 & 0.55 \\
\hline & M3 & 0.37 & 0.58 & - & - & 0.24 & 0.37 \\
\hline & M4 & 0.24 & 0.39 & - & - & 0.21 & 0.29 \\
\hline & M5 & 0.14 & 0.79 & - & - & 0.08 & 0.53 \\
\hline & M6 & 0.33 & 0.52 & - & - & 0.08 & 0.19 \\
\hline
\end{tabular}

Note. Rats in the Less-Enriched Group were not exposed to the VI 60 -s VT 30-s component; rats in the More-Enriched Group were not exposed to the VI 60-s VT 120-s component. 
Tolerance ratios, constructed by dividing the AUC of the chronic dose-effect function by the AUC of the acute dose-effect function, were calculated to quantify the extent to which tolerance developed in both components of the multiple schedule. Tolerance ratios are shown in Figure 5 for rats in both groups. Values greater than 1.0 indicate tolerance occurred, and values less than 1.0 indicate sensitization occurred. Visual inspection of Figure 5 indicates that tolerance ratios were not systematically related to component or group. This was confirmed by a repeated-measure ANOVA with group as a between-subject factor and component as a withinsubject factor, which indicated that there was no statistically significant group by component interaction $[F(1,10)=.001, p>.05]$ or main effect of component $[F(1,10)=1.67, p>.05]$ on tolerance ratios. Lever-press rates during baseline were not systematically related to the development of tolerance (i.e., tolerance ratios) for rats in either group in components with noncontingent food pellets [Less-Enriched Group, $r(4)=.22, p>.05$; More-Enriched Group, $r(4)=$ $.13, p>.05]$ or in components without non-contingent food pellets [Less-Enriched Group, $r(4)=$ $.03, p>.05$; More-Enriched Group, $r(4)=.22, p>.05]$. The extent to which acute injections of the individually selected repeated dose of $d$-amphetamine reduced the number of food pellets earned (i.e., how much reinforcement loss occurred) compared to acute injections of saline was also not systematically related to tolerance ratios for rats in either group in components with noncontingent food pellets [Less-Enriched Group, $r(4)=.38, p>.05$; More-Enriched Group, $r(4)=$ $-.41, p>.05$ ] or in components without non-contingent food pellets [Less-Enriched Group, $r(4)$ $=-.61, p>.05 ;$ More-Enriched Group, $r(4)=-.56, p>.05]$.

Collapsing data across groups, however, revealed a statistically significant negative correlation between the size of the repeatedly administered dose and tolerance ratios in components with non-contingent food pellets $[r(10)=-.58, p=.049]$ and components without 
non-contingent food pellets $[r(10)=-0.59, p=.04]$. This indicates that tolerance developed to a greater extent (i.e., larger tolerance ratios were obtained) for rats that had smaller repeatedly administered doses compared to rats that had larger repeatedly administered doses. For example, the dose of $d$-amphetamine repeatedly administered for rat L4 was $2.3 \mathrm{mg} / \mathrm{kg}$, which was one of the larger repeatedly administered doses, and tolerance for this rat did not develop. For rat M5, the dose of $d$-amphetamine repeatedly administered was $0.8 \mathrm{mg} / \mathrm{kg}$. This was the smallest repeatedly administered dose, and tolerance for this rat developed to the greatest extent. The correlation between tolerance ratios and the size of the repeatedly administered dose was not statistically significant, however, when data from rat L4, which had the smallest tolerance ratio, or rat M5, which had the largest tolerance ratio, were excluded from analysis.

Although the delivery of non-contingent food pellets did not differentially affect the development of tolerance it is possible that non-contingent food pellet delivery influenced recovery from the rate-decreasing effects of the repeatedly administered dose of $d$-amphetamine. This possibility was explored by plotting lever-press rates following injections of the individually selected repeated dose of $d$-amphetamine during the acute, chronic, and repeated (i.e., first 45 days of repeated injections) phases for each rat in the Less-Enriched Group (Figure 6) and the More-Enriched Group (Figure 7). Visual inspection of these figures indicates that recovery from the rate-decreasing effect of the repeatedly administered dose of $d$-amphetamine was not systematically related to the delivery of non-contingent food pellets. 


\section{Less-Enriched Group}
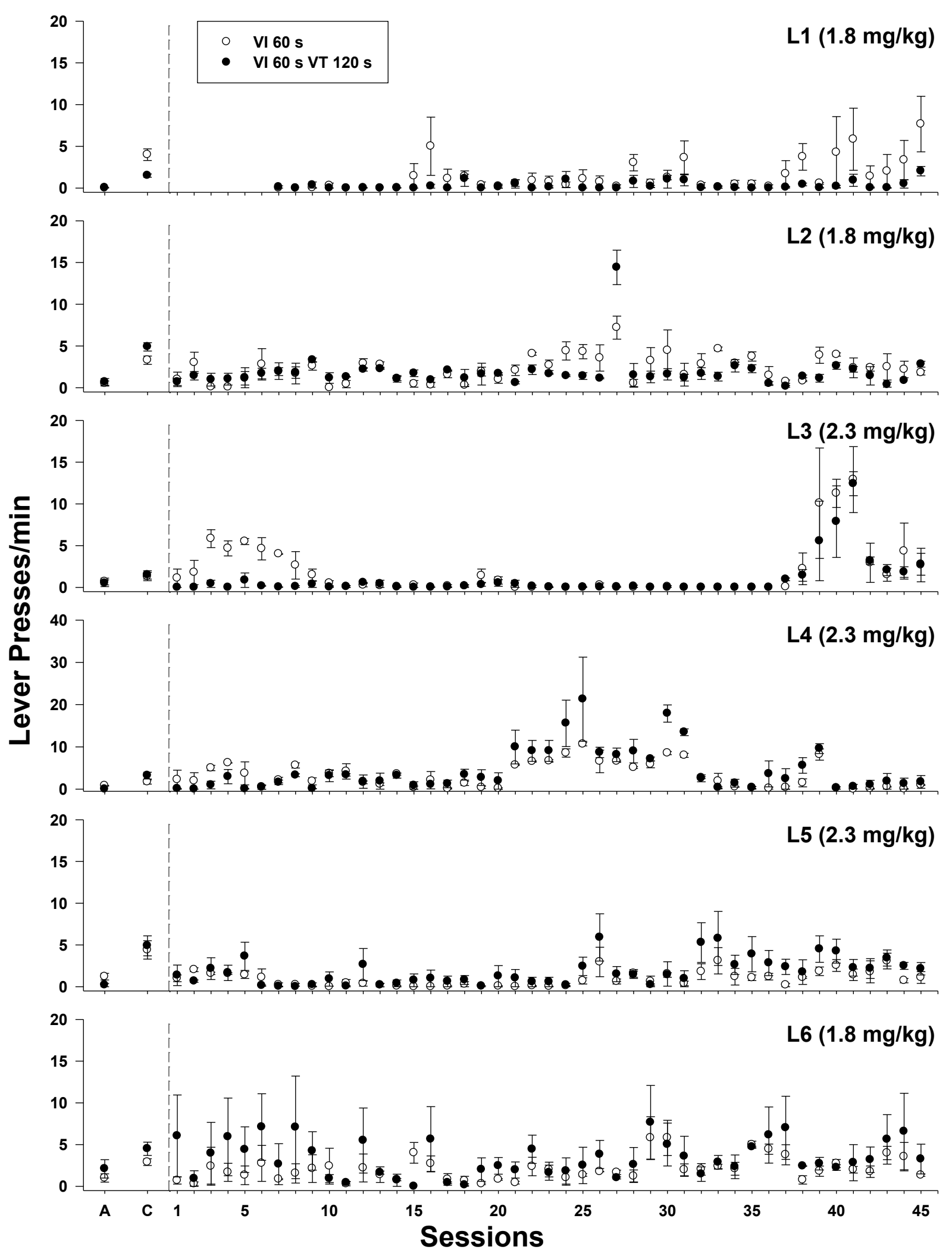
Figure 6. Mean lever presses/min from sessions in which the individually selected repeated dose of $d$-amphetamine was injected for the acute, chronic, and repeated phases for each rat (rows) in the Less-Enriched Group. The repeated dose of $d$-amphetamine is indicated in parenthesis next to rat identification. Data from components without non-contingent food pellets are indicated by open circles; closed circles represent data from components with non-contingent food pellets.

Error bars represent \pm 1 SEM. Data for the acute and chronic phases are to the left of the verticaldashed line and represented by $\mathrm{A}$ and $\mathrm{C}$, respectively. For the acute phase, data are from all injections of the repeated dose. For the chronic phase, data are from sessions conducted the day before probe sessions. Data for the repeated phase are to the right of the vertical-dashed line, and are from the first 45 sessions in which the repeated dose was injected. The first 6 sessions of the repeated phase for rat L1 are omitted because a smaller repeated dose (i.e., $1.0 \mathrm{mg} / \mathrm{kg}$ ) was injected during those sessions (see text for details). Note that the $y$-axis is scaled differently for rat L4. 


\section{More-Enriched Group}
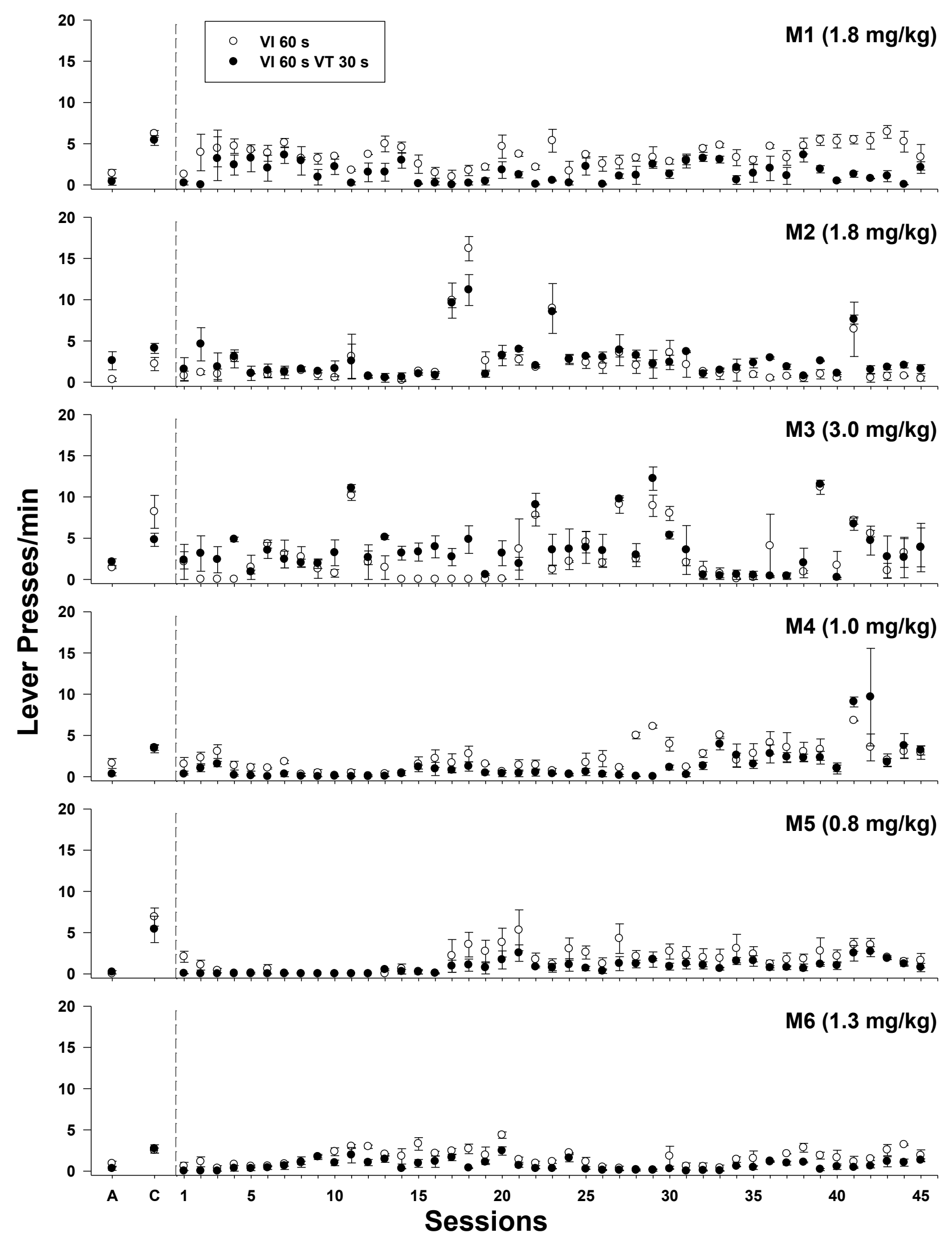
Figure 7. Mean lever presses/min from sessions in which the individually selected repeated dose of $d$-amphetamine was injected for the acute, chronic, and repeated phases for each rat (rows) in the More-Enriched Group. The repeated dose of $d$-amphetamine is indicated in parenthesis next to rat identification. Data from components without non-contingent food pellets are indicated by open circles; closed circles represent data from components with non-contingent food pellets. Error bars represent \pm 1 SEM. Data for the acute and chronic phases are to the left of the vertical-dashed line and represented by $\mathrm{A}$ and $\mathrm{C}$, respectively. For the acute phase, data are from all injections of the repeated dose. For the chronic phase, data are from sessions conducted the day before probe sessions. Data for the repeated phase are to the right of the vertical-dashed line, and are from the first 45 sessions in which the repeated dose was injected. 


\section{Response-bout Analysis}

Baseline. Log-survivor functions constructed from IRTs for the last six stable baseline sessions for each component are shown in Figure 8 for rats in the Less-Enriched Group and Figure 9 for rats in the More-Enriched Group. Fit lines represent the best fitting doubleexponential equation. A clear broken-stick appearance in the log-survivor functions was not readily observed for the majority of rats in either group, and in many cases the log-survivor functions looked similar for both components. This indicates that IRTs were similar between the two components. For the few rats (rat L2, Figure 8; rat M6, Figure 9) in which a clear brokenstick appearance in the log-survivor function was observed in both components, the break tended to occur at different points. This indicates that IRTs were different between the two components for these rats.

Table 6 lists estimates of bout-initiation $(b)$ and within-bout $(w)$ rates from the best fitting double-exponential function (see above for equation). The $r^{2}$ values, which ranged from .86.99 , are also listed and they indicate that the data were described reasonably by the doubleexponential function. Bout-initiation and within-bout rates, however, were the same in at least one component for seven of the 12 rats. This supports the visual analysis described above, which indicated that bout-initiation and within-bout rates would be similar for rats in which clear breaks in the log-survivor functions were not apparent. For these rats, bout-initiation and within-bout rates were the same because the log-survivor function for these components was described best by a single-exponential function rather than the double-exponential function. Data from the seven rats in which it was not possible to classify lever presses as either starting a bout or occurring within a bout were excluded from further analysis. A two-way repeated-measure ANOVA with group as a between subject factor and component as a within subject factor 
indicated that there was no statistically significant group by component interaction for boutinitiation responses $[F(1,3)=2.83, p>.05]$ or within-bout responses $[F(1,3)=2.81, p>.05]$ or main effect of bout-initiation responses $[F(1,3)=6.88, p>.05]$ or within-bout responses $[F(1,3)$ $=0.48, p>.05]$.

Acute and chronic phases. Log-survivor functions were constructed from IRTs collapsed across sessions in which saline or doses of $d$-amphetamine were administered for the acute and chronic phases. Estimates of bout-initiation $(b)$ and within-bout $(w)$ rates (in responses/s) from the best fitting double-exponential function fit to these log-survivor functions are shown in Table 7 for rats in the Less-Enriched Group and Table 8 for rats in the MoreEnriched Group. The $r^{2}$ values, which ranged from $.84-.99$, are also listed. In most cases data were described adequately by the double-exponential function. However, for all rats in both groups, estimates of bout-initiation and within-bout rates were the same across several of the doses tested. As mentioned above, this occurred because the log-survivor function for these components was described best by a single exponential. It is therefore not possible to classify these responses as starting a bout or occurring within a bout. Due to the large number of cases in which estimates of bout-initiation and within-bout rates were the same, and the variations in these estimates obtained when larger doses of $d$-amphetamine were tested (which was likely due to fitting the double-exponential equation to log-survivor plots with relatively few IRTs) it was not possible to compare accurately the acute and chronic effects of $d$-amphetamine, or assess the development of tolerance using bout-initiation and within-bout rates. 
Less-Enriched Group
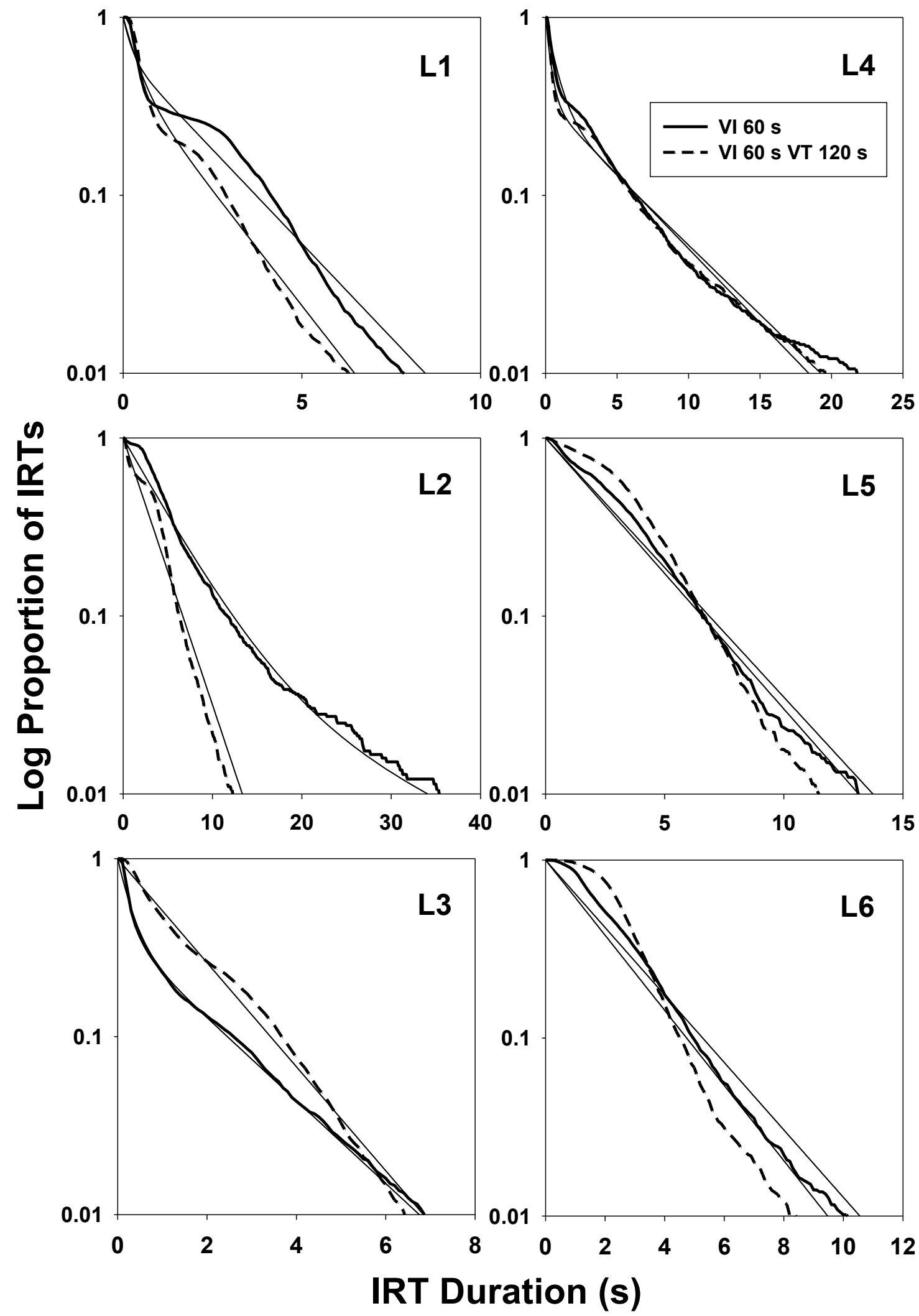
Figure 8. Log-survivor functions of IRT distributions collapsed across the last six stable baseline sessions for rats in the Less-Enriched Group. Log proportions of IRTs are plotted as a function of IRT Duration (s). Solid lines represent lever presses in the component without noncontingent food pellets. Dashed lines represent lever presses in the component with noncontingent food pellets. Fit lines represent the best fitting double-exponential equation. The $x$ axis is scaled differences across rats. 


\section{More-Enriched Group}
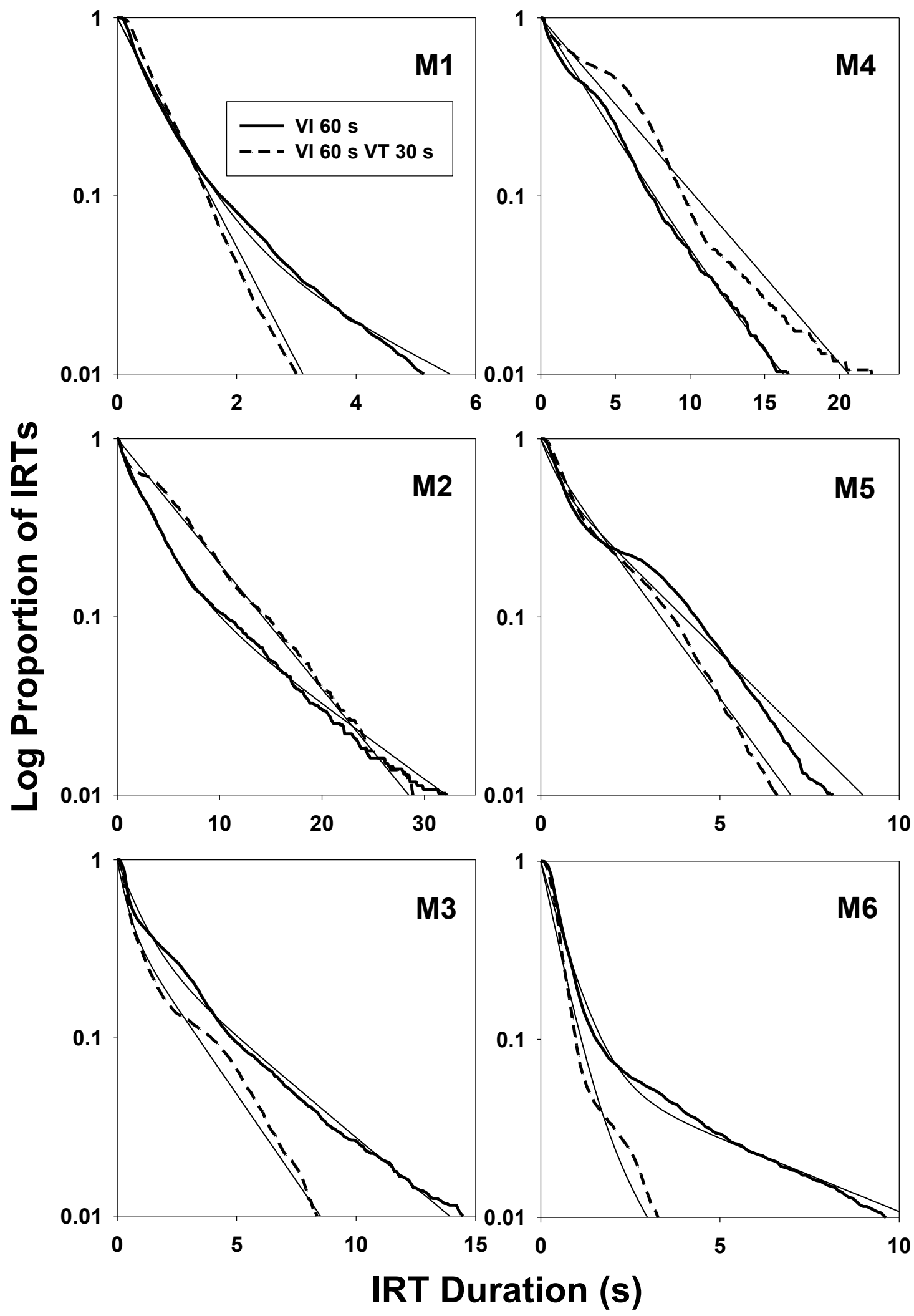
Figure 9. Log-survivor functions of IRT distributions collapsed across the last six baseline sessions for rats in the More-Enriched Group. Log proportions of IRTs are plotted as a function of IRT Duration (s). Solid lines represent lever presses in the component without non-contingent food pellets. Dashed lines represent lever presses in the component with non-contingent food pellets. Fit lines represent the best fitting double-exponential equation. The $x$-axis is scaled differences across rats. 
Table 6

Estimates of Bout-Initiation (b) and Within-Bout (w) Responses/s and $r^{2}$ values for the Best Fitting Double-Exponential Function during Baseline for the Multiple Schedule Components for Rats in both Groups

\begin{tabular}{|c|c|c|c|c|c|c|c|c|c|c|}
\hline \multirow{3}{*}{ Group } & \multirow{3}{*}{ Subject } & \multicolumn{9}{|c|}{ Component } \\
\hline & & \multicolumn{3}{|c|}{ VI $60 \mathrm{~s}$} & \multicolumn{3}{|c|}{ VI $60 \mathrm{~s} \mathrm{VT} 120 \mathrm{~s}$} & \multicolumn{3}{|c|}{ VI $60 \mathrm{~s}$ VT $30 \mathrm{~s}$} \\
\hline & & $b$ & $w$ & $r^{2}$ & $b$ & $w$ & $r^{2}$ & $b$ & $w$ & $r^{2}$ \\
\hline \multirow{6}{*}{$\begin{array}{l}\text { Less- } \\
\text { Enriched }\end{array}$} & L1 & 0.49 & 4.55 & .96 & 0.60 & 2.64 & .97 & - & - & - \\
\hline & L2 & 0.05 & 0.21 & .96 & $0.35^{*}$ & $0.35^{*}$ & .95 & - & - & - \\
\hline & L3 & 0.54 & 3.66 & .99 & $0.67^{*}$ & $0.67 *$ & .99 & - & - & - \\
\hline & L4 & 0.18 & 1.33 & .97 & 0.19 & 2.80 & .98 & - & - & - \\
\hline & L5 & $0.34^{*}$ & $0.34^{*}$ & .98 & $0.35^{*}$ & $0.35 *$ & .90 & - & - & - \\
\hline & L6 & $0.44^{*}$ & $0.44^{*}$ & .96 & $0.49^{*}$ & $0.49 *$ & .86 & - & - & - \\
\hline \multirow{6}{*}{$\begin{array}{l}\text { More- } \\
\text { Enriched }\end{array}$} & M1 & 0.40 & 1.68 & .99 & - & - & - & $1.48^{*}$ & $1.48 *$ & .98 \\
\hline & M2 & 0.10 & 0.39 & .99 & - & - & - & $0.16^{*}$ & $0.16^{*}$ & .99 \\
\hline & M3 & 0.26 & 1.17 & .99 & - & - & - & 0.45 & 2.58 & .98 \\
\hline & M4 & 0.08 & 0.31 & .99 & - & - & - & $0.22 *$ & $0.22 *$ & .96 \\
\hline & M5 & 0.46 & 2.62 & .97 & - & - & - & 0.63 & 2.24 & .99 \\
\hline & M6 & 0.19 & 1.74 & .97 & - & - & - & 0.66 & 2.30 & .95 \\
\hline
\end{tabular}

Note. Asterisks (*) indicate estimates of bout-initiation and within-bout responses/s that were the same. Rats in the Less-Enriched Group were not exposed to the VI 60-s VT 30-s component; rats in the More-Enriched Group were not exposed to the VI 60-s VT 120-s component. 
Table 7

Estimates of Bout-Initiation (b) and Within-Bout (w) Responses/s and $r^{2}$ values from the Best Fitting DoubleExponential Function for the Doses of Saline and d-Amphetamine Tested during the Acute and Chronic Phases for the Multiple Schedule Components for Rats in the Less-Enriched Group

\begin{tabular}{|c|c|c|c|c|c|c|c|c|c|c|c|c|c|}
\hline \multirow{4}{*}{ Subject } & \multirow{4}{*}{ Dose } & \multicolumn{12}{|c|}{ Component } \\
\hline & & \multicolumn{6}{|c|}{ VI $60 \mathrm{~s}$} & \multicolumn{6}{|c|}{ VI $60 \mathrm{~s}$ VT $120 \mathrm{~s}$} \\
\hline & & \multicolumn{3}{|c|}{ Acute } & \multicolumn{3}{|c|}{ Chronic } & \multicolumn{3}{|c|}{ Acute } & \multicolumn{3}{|c|}{ Chronic } \\
\hline & & $b$ & $w$ & $r^{2}$ & $b$ & $w$ & $r^{2}$ & $b$ & $w$ & $r^{2}$ & $b$ & $w$ & $r^{2}$ \\
\hline \multirow[t]{7}{*}{ L1 } & Saline & 0.29 & 4.40 & .98 & 0.06 & 0.33 & .97 & 0.51 & 3.79 & .98 & 0.38 & 2.13 & .99 \\
\hline & 0.1 & $0.39 *$ & $0.39 *$ & .97 & $0.31 *$ & $0.31^{*}$ & .95 & 0.43 & 3.41 & .98 & 0.45 & 2.86 & .98 \\
\hline & 0.3 & $0.28 *$ & $0.28 *$ & .97 & $0.31^{*}$ & $0.31^{*}$ & .93 & 0.36 & 5.26 & .97 & $0.45^{*}$ & $0.45^{*}$ & .98 \\
\hline & 0.6 & $0.21 *$ & $0.21 *$ & .97 & $0.30^{*}$ & $0.30^{*}$ & .94 & $0.26^{*}$ & $0.26^{*}$ & .98 & 0.20 & 0.64 & .99 \\
\hline & 1.0 & 0.01 & 0.08 & .95 & 0.01 & 0.21 & .98 & 0.01 & 0.16 & .97 & 0.18 & 0.29 & .99 \\
\hline & 1.8 & - & - & - & 0.01 & 0.08 & .99 & - & - & - & 0.00 & 0.04 & .99 \\
\hline & 3.0 & - & - & - & 0.00 & 0.00 & 1.0 & - & - & - & - & - & - \\
\hline \multirow[t]{6}{*}{ L2 } & Saline & 0.06 & 0.22 & .97 & 0.02 & 0.20 & .98 & 0.05 & 0.31 & .98 & $0.32 *$ & $0.32 *$ & .96 \\
\hline & 0.1 & 0.03 & 0.13 & .97 & $0.24 *$ & $0.24 *$ & .98 & 0.02 & 0.24 & .99 & $0.36^{*}$ & $0.36^{*}$ & .95 \\
\hline & 0.3 & $0.09 *$ & $0.09^{*}$ & .96 & $0.24 *$ & $0.24 *$ & .95 & $0.17^{*}$ & $0.17^{*}$ & .97 & $0.40^{*}$ & $0.40^{*}$ & .89 \\
\hline & 1.0 & 0.01 & 0.10 & .99 & 0.03 & 0.14 & .97 & 0.02 & 0.09 & .98 & 0.01 & 0.15 & .97 \\
\hline & 1.8 & 0.01 & 0.06 & .97 & 0.01 & 0.06 & .99 & 0.00 & 0.02 & .98 & 0.02 & 0.09 & .98 \\
\hline & 3.0 & - & - & - & 0.03 & 0.05 & .95 & - & - & - & 0.00 & 0.06 & .97 \\
\hline \multirow[t]{8}{*}{ L3 } & Saline & 0.15 & 0.85 & .96 & $0.64 *$ & $0.64 *$ & .97 & $0.57^{*}$ & $0.57 *$ & .98 & $0.47^{*}$ & $0.47 *$ & .92 \\
\hline & 0.1 & 0.45 & 1.70 & .99 & 0.09 & 0.62 & .98 & $0.61 *$ & $0.61 *$ & .99 & $0.54 *$ & $0.54 *$ & .90 \\
\hline & 0.3 & 0.51 & 5.28 & .99 & $0.50^{*}$ & $0.50^{*}$ & .97 & 0.04 & 0.45 & .99 & $0.51^{*}$ & $0.51 *$ & .92 \\
\hline & 0.6 & $0.18^{*}$ & $0.18^{*}$ & .93 & $0.58^{*}$ & $0.58^{*}$ & .95 & $0.17^{*}$ & $0.17 *$ & .96 & $0.52 *$ & $0.52 *$ & .87 \\
\hline & 1.0 & 0.01 & 0.11 & .98 & 0.08 & 0.35 & .99 & 0.01 & 0.12 & .98 & $0.34 *$ & $0.34 *$ & .92 \\
\hline & 1.8 & 0.01 & 0.06 & .97 & 0.01 & 0.06 & .94 & 0.00 & 0.06 & .91 & 0.00 & 0.08 & .97 \\
\hline & 2.3 & 0.00 & 0.03 & .98 & 0.01 & 0.10 & .98 & 0.00 & 0.05 & .92 & 0.01 & 0.07 & .99 \\
\hline & 3.0 & - & - & - & 0.00 & 0.03 & .94 & - & - & - & - & - & - \\
\hline
\end{tabular}


Table 7 continued

\begin{tabular}{|c|c|c|c|c|c|c|c|c|c|c|c|c|c|}
\hline \multirow{4}{*}{ Subject } & \multirow{4}{*}{ Dose } & \multicolumn{12}{|c|}{ Component } \\
\hline & & \multicolumn{6}{|c|}{ VI $60 \mathrm{~s}$} & \multicolumn{6}{|c|}{ VI $60 \mathrm{~s}$ VT $120 \mathrm{~s}$} \\
\hline & & \multicolumn{3}{|c|}{ Acute } & \multicolumn{3}{|c|}{ Chronic } & \multicolumn{3}{|c|}{ Acute } & \multicolumn{3}{|c|}{ Chronic } \\
\hline & & $b$ & $w$ & $r^{2}$ & $b$ & $w$ & $r^{2}$ & $b$ & $w$ & $r^{2}$ & $b$ & $w$ & $r^{2}$ \\
\hline \multirow[t]{8}{*}{ L4 } & Saline & 0.09 & 0.91 & .99 & 0.29 & 3.24 & .99 & 0.10 & 1.62 & .98 & 0.41 & 3.92 & .98 \\
\hline & 0.1 & 0.10 & 1.21 & .98 & 0.24 & 3.84 & .99 & 0.09 & 0.54 & .96 & 0.42 & 3.96 & .97 \\
\hline & 0.3 & 0.18 & 1.58 & .99 & $0.23^{*}$ & $0.23 *$ & .96 & 0.13 & 2.16 & .99 & $0.40^{*}$ & $0.40 *$ & .98 \\
\hline & 1.0 & 0.00 & 0.07 & .99 & $0.09 *$ & $0.09 *$ & .89 & 0.01 & 0.05 & .98 & $0.14^{*}$ & $0.14 *$ & .98 \\
\hline & 1.3 & 0.01 & 0.05 & .99 & 0.00 & 0.06 & .91 & 0.00 & 0.09 & .95 & 0.01 & 0.09 & .99 \\
\hline & 1.8 & 0.00 & 0.04 & .97 & 0.02 & 0.07 & .97 & 0.01 & 0.06 & .98 & 0.01 & 0.08 & .99 \\
\hline & 2.3 & 0.00 & 0.03 & .97 & 0.00 & 0.07 & .98 & - & - & - & 0.00 & 0.09 & .98 \\
\hline & 3.0 & - & - & - & - & - & - & - & - & - & - & - & - \\
\hline \multirow[t]{7}{*}{ L5 } & Saline & $0.30 *$ & $0.30^{*}$ & .94 & $0.32 *$ & $0.32 *$ & .95 & $0.43 *$ & $0.43^{*}$ & .87 & $0.40 *$ & $0.40^{*}$ & .95 \\
\hline & 0.1 & $0.28 *$ & $0.28^{*}$ & .95 & $0.37^{*}$ & $0.37 *$ & .93 & $0.44 *$ & $0.44^{*}$ & .91 & $0.50^{*}$ & $0.50 *$ & .80 \\
\hline & 0.3 & $0.32 *$ & $0.32 *$ & .97 & 0.43 & 5.04 & .97 & $0.39 *$ & $0.39 *$ & .95 & 0.53 & 5.84 & .95 \\
\hline & 1.0 & 0.007 & 0.11 & .96 & 0.01 & 0.14 & .95 & 0.10 & 0.18 & .99 & $0.20 *$ & $0.20 *$ & .97 \\
\hline & 1.8 & 0.017 & 0.07 & .99 & 0.00 & 0.09 & .94 & 0.02 & 0.06 & .99 & $0.10^{*}$ & $0.10 *$ & .87 \\
\hline & 2.3 & 0.020 & 0.07 & .96 & 0.01 & 0.09 & .99 & - & - & - & 0.03 & 0.10 & .99 \\
\hline & 3.0 & - & - & - & 0.05 & 0.05 & .94 & - & - & - & - & - & - \\
\hline \multirow[t]{6}{*}{ L6 } & Saline & $0.54 *$ & $0.54 *$ & .99 & 0.12 & 0.51 & .98 & 0.49 & 0.54 & .91 & $0.47 *$ & $0.47 *$ & .97 \\
\hline & 0.1 & $0.56^{*}$ & $0.56^{*}$ & .96 & 0.16 & 0.54 & .99 & $0.59 *$ & $0.59 *$ & .87 & $0.44^{*}$ & $0.44 *$ & .96 \\
\hline & 0.3 & $0.39 *$ & $0.39 *$ & .98 & 0.07 & 0.43 & .99 & $0.36^{*}$ & $0.36^{*}$ & .92 & $0.45^{*}$ & $0.45^{*}$ & .96 \\
\hline & 1.0 & $0.17^{*}$ & $0.17^{*}$ & .96 & 0.24 & 0.91 & .99 & 0.00 & 0.15 & .98 & $0.32 *$ & $0.32 *$ & .99 \\
\hline & 1.8 & 0.01 & 0.08 & .97 & 0.01 & 0.05 & .99 & 0.00 & 0.08 & .97 & 0.01 & 0.08 & .99 \\
\hline & 3.0 & - & - & - & 0.00 & 0.03 & .96 & - & - & - & $0.03^{*}$ & $0.03 *$ & .98 \\
\hline
\end{tabular}

Note. Asterisks $(*)$ indicate estimates of bout-initiation and within-bout responses/s that were the same. Dashes indicate doses that completely suppressed lever pressing; estimates for these doses were not calculated. 
Table 8

Estimates of Bout-Initiation (b) and Within-Bout (w) Responses/s and $r^{2}$ values for the Best Fitting DoubleExponential Function for the Doses of Saline and d-Amphetamine Tested during the Acute and Chronic Phases for the Multiple Schedule Components for Rats in the More-Enriched Group

\begin{tabular}{|c|c|c|c|c|c|c|c|c|c|c|c|c|c|}
\hline \multirow{4}{*}{ Subject } & \multirow{4}{*}{ Dose } & \multicolumn{12}{|c|}{ Component } \\
\hline & & \multicolumn{6}{|c|}{ VI $60 \mathrm{~s}$} & \multicolumn{6}{|c|}{ VI $60 \mathrm{~s}$ VT $30 \mathrm{~s}$} \\
\hline & & \multicolumn{3}{|c|}{ Acute } & \multicolumn{3}{|c|}{ Chronic } & \multicolumn{3}{|c|}{ Acute } & \multicolumn{3}{|c|}{ Chronic } \\
\hline & & $b$ & $W$ & $r^{2}$ & $b$ & $w$ & $r^{2}$ & $b$ & $w$ & $r^{2}$ & $b$ & $w$ & $r^{2}$ \\
\hline \multirow[t]{8}{*}{ M1 } & Saline & 0.43 & 2.70 & .99 & 0.41 & 4.59 & .97 & 0.49 & 1.81 & .99 & 0.54 & 4.19 & .97 \\
\hline & 0.1 & 0.57 & 3.93 & .98 & 0.54 & 3.82 & .99 & 0.47 & 2.40 & .99 & 0.47 & 3.70 & .96 \\
\hline & 0.3 & 0.37 & 3.88 & .99 & 0.52 & 5.87 & .98 & 0.44 & 3.03 & .99 & 0.53 & 5.96 & .95 \\
\hline & 0.6 & 0.21 & 0.81 & .99 & 0.51 & 5.39 & .96 & 0.08 & 0.23 & .99 & 0.56 & 4.66 & .95 \\
\hline & 1.0 & 0.00 & 0.12 & .99 & $0.22 *$ & $0.22 *$ & .87 & 0.02 & 0.10 & .98 & 0.00 & 0.17 & .95 \\
\hline & 1.3 & 0.00 & 0.06 & .98 & $0.20^{*}$ & $0.20 *$ & .94 & 0.01 & 0.06 & .97 & $0.21^{*}$ & $0.21^{*}$ & .91 \\
\hline & 1.8 & 0.01 & 0.04 & .99 & 0.01 & 0.12 & .95 & - & - & - & 0.01 & 0.12 & .97 \\
\hline & 3.0 & - & - & - & $0.10^{*}$ & $0.10^{*}$ & .96 & - & - & - & 0.00 & 0.13 & .94 \\
\hline \multirow[t]{7}{*}{ M2 } & Saline & 0.03 & 0.20 & .99 & 0.05 & 0.22 & .99 & $0.17^{*}$ & $0.17 *$ & .85 & $0.22 *$ & $0.22 *$ & .90 \\
\hline & 0.1 & 0.06 & 0.20 & .98 & 0.04 & 0.22 & .97 & $0.14 *$ & $0.14^{*}$ & .90 & $0.25^{*}$ & $0.25^{*}$ & .87 \\
\hline & 0.3 & 0.01 & 0.12 & .99 & 0.03 & 0.26 & .95 & 0.06 & 0.07 & .99 & $0.25^{*}$ & $0.25^{*}$ & .87 \\
\hline & 0.6 & 0.00 & 0.09 & .97 & 0.04 & 0.24 & .96 & 0.02 & 0.09 & .98 & $0.21 *$ & $0.21 *$ & .89 \\
\hline & 1.0 & 0.01 & 0.06 & .98 & 0.00 & 0.07 & .99 & $0.06^{*}$ & $0.06^{*}$ & .99 & $0.13^{*}$ & $0.13^{*}$ & .94 \\
\hline & 1.8 & - & - & - & 0.01 & 0.08 & .97 & 0.01 & 0.08 & .99 & 0.19 & 0.10 & .98 \\
\hline & 3.0 & $0.05^{*}$ & $0.05^{*}$ & .96 & 0.00 & 0.02 & .98 & - & - & - & 0.01 & 0.06 & .97 \\
\hline \multirow[t]{5}{*}{ M3 } & Saline & 0.32 & 3.38 & .96 & $0.48^{*}$ & $0.48^{*}$ & .95 & 0.43 & 4.46 & .94 & 0.47 & 4.04 & .96 \\
\hline & 0.3 & 0.34 & 3.89 & .98 & $0.42 *$ & $0.42 *$ & .97 & 0.38 & 4.32 & .97 & 0.50 & 5.14 & .95 \\
\hline & 1.0 & 0.06 & 0.24 & .99 & $0.37 *$ & $0.37 *$ & .97 & $0.13^{*}$ & $0.13^{*}$ & .99 & 0.36 & 8.03 & .94 \\
\hline & 1.8 & 0.02 & 0.14 & .98 & $0.25^{*}$ & $0.25^{*}$ & .92 & 0.00 & 0.09 & .97 & $0.16^{*}$ & $0.16^{*}$ & .84 \\
\hline & 3.0 & 0.02 & 0.09 & .97 & 0.00 & 0.18 & .96 & 0.00 & 0.11 & .94 & 0.01 & 0.11 & .97 \\
\hline
\end{tabular}


Table 8 continued

\begin{tabular}{|c|c|c|c|c|c|c|c|c|c|c|c|c|c|}
\hline \multirow{4}{*}{ Subject } & \multirow{4}{*}{ Dose } & \multicolumn{12}{|c|}{ Component } \\
\hline & & \multicolumn{6}{|c|}{ VI $60 \mathrm{~s}$} & \multicolumn{6}{|c|}{ VI $60 \mathrm{~s}$ VT $30 \mathrm{~s}$} \\
\hline & & \multicolumn{3}{|c|}{ Acute } & \multicolumn{3}{|c|}{ Chronic } & \multicolumn{3}{|c|}{ Acute } & \multicolumn{3}{|c|}{ Chronic } \\
\hline & & $b$ & $w$ & $r^{2}$ & $b$ & $w$ & $r^{2}$ & $b$ & $w$ & $r^{2}$ & $b$ & $w$ & $r^{2}$ \\
\hline \multirow[t]{6}{*}{ M4 } & Saline & 0.09 & 0.35 & .99 & $0.21 *$ & $0.21 *$ & .96 & $0.22 *$ & $0.22 *$ & .98 & $0.32 *$ & $0.32 *$ & .96 \\
\hline & 0.1 & 0.10 & 0.27 & .99 & $0.22 *$ & $0.22 *$ & .95 & $0.20^{*}$ & $0.20 *$ & .98 & $0.28^{*}$ & $0.28 *$ & .91 \\
\hline & 0.3 & $0.11 *$ & $0.11^{*}$ & .97 & $0.17 *$ & $0.17^{*}$ & .86 & $0.13 *$ & $0.13^{*}$ & .97 & $0.19^{*}$ & $0.19^{*}$ & .92 \\
\hline & 0.6 & $0.06^{*}$ & $0.06^{*}$ & .97 & $0.10^{*}$ & $0.10^{*}$ & .95 & 0.00 & 0.06 & .98 & $0.12 *$ & $0.12^{*}$ & .93 \\
\hline & 1.0 & 0.00 & 0.04 & .99 & 0.01 & 0.05 & .99 & - & - & - & 0.00 & 0.05 & .99 \\
\hline & 1.8 & - & - & - & - & - & - & - & - & - & - & - & - \\
\hline \multirow[t]{7}{*}{ M5 } & Saline & $0.21 *$ & $0.21^{*}$ & .97 & $0.32 *$ & $0.32 *$ & .87 & $0.33^{*}$ & $0.33^{*}$ & .97 & $0.46^{*}$ & $0.46^{*}$ & .95 \\
\hline & 0.1 & $0.08 *$ & $0.08^{*}$ & .97 & $0.28 *$ & $0.28^{*}$ & .94 & 0.04 & 0.10 & 1.0 & $0.40^{*}$ & $0.40^{*}$ & .95 \\
\hline & 0.2 & $0.04 *$ & $0.04^{*}$ & .93 & $0.30 *$ & $0.30 *$ & .92 & 0.00 & 0.04 & .96 & $0.32 *$ & $0.32 *$ & .94 \\
\hline & 0.3 & 0.00 & 0.04 & .99 & $0.26^{*}$ & $0.26^{*}$ & .95 & 0.00 & 0.06 & 1.0 & $0.30^{*}$ & $0.30 *$ & .96 \\
\hline & 0.6 & 0.01 & 0.08 & .96 & $0.30 *$ & $0.30 *$ & .89 & 0.01 & 0.07 & .99 & $0.34^{*}$ & $0.34 *$ & .92 \\
\hline & 0.8 & - & - & - & 0.00 & 0.11 & .97 & - & - & - & 0.03 & 0.13 & .99 \\
\hline & 1.0 & - & - & - & 0.02 & 0.08 & .96 & - & - & - & 0.01 & 0.10 & .98 \\
\hline \multirow[t]{8}{*}{ M6 } & Saline & 0.07 & 0.46 & .99 & 0.05 & 0.18 & .99 & 0.31 & 1.56 & .99 & 0.35 & 2.43 & .99 \\
\hline & 0.1 & 0.06 & 0.21 & .99 & 0.05 & 0.14 & .99 & 0.30 & 1.84 & .99 & 0.40 & 2.62 & .99 \\
\hline & 0.3 & 0.16 & 1.35 & .98 & $0.23 *$ & $0.23 *$ & .95 & 0.14 & 1.69 & .94 & $0.33^{*}$ & $0.33^{*}$ & .96 \\
\hline & 0.6 & 0.02 & 0.13 & .99 & $0.26^{*}$ & $0.26^{*}$ & .97 & 0.02 & 0.08 & .99 & $0.25^{*}$ & $0.25 *$ & .98 \\
\hline & 1.0 & 0.02 & 0.12 & .94 & $0.10^{*}$ & $0.10^{*}$ & .98 & 0.01 & 0.09 & .97 & 0.05 & 0.22 & .99 \\
\hline & 1.3 & 0.00 & 0.04 & .99 & 0.10 & 0.05 & .99 & - & - & - & 0.01 & 0.10 & .97 \\
\hline & 1.8 & - & - & - & $0.03 *$ & $0.03 *$ & .98 & 0.00 & 0.08 & .93 & 0.00 & 0.02 & .99 \\
\hline & 3.0 & - & - & - & - & - & - & - & - & - & - & - & - \\
\hline
\end{tabular}

Note. Asterisks $(*)$ indicate estimates of bout-initiation and within-bout responses/s that were the same. Dashes indicate doses that completely suppressed lever pressing; estimates for these doses were not calculated. 


\section{Discussion}

\section{Overall}

The present study was designed to determine if enriching the environment by providing food pellets independent of behavior (i.e., non-contingently) during experimental sessions influences the development of behavioral tolerance. Food pellets were provided noncontingently at a relatively low rate for one group of rats, and at a relatively high rate for another group of rats. For both groups, tolerance developed to a similar extent in components with and without non-contingent food pellets. These findings indicate that enriching the environment by providing non-contingent food pellets does not differentially affect the development of tolerance to the rate-decreasing effects of $d$-amphetamine in rats.

Dallery and Lancaster (1999) found that tolerance to the rate-decreasing effects of $d$ amphetamine in rats was correlated with the environmental context, as measured by the parameter $R_{\mathrm{o}}$ in Herrnstein's (1970) single-alternative matching equation. In their study, lever pressing for food pellets by rats was maintained under a multiple schedule with five different VI components. Although the environmental context varied widely across rats during seemingly equivalent baseline conditions, tolerance developed to a greater extent for rats with leaner environmental contexts (i.e., smaller values of $R_{\mathrm{o}}$ ) than more enriched environmental contexts (i.e., larger values of $R_{\mathrm{o}}$ ). It has been previously shown that values of $R_{\mathrm{o}}$ increase with increases in the rate at which non-contingent food is provided (Rachlin and Baum, 1972). To explore further the role the environmental context has on the development of tolerance the present study manipulated the rate at which non-contingent food pellets were provided to rats that lever pressed for food pellets. Lever pressing for food pellets was maintained under a multiple schedule consisting of two VI 60-s components. Non-contingent food pellets were provided in 
one of those components at a lower rate for one group of rats and at a higher rate for another group of rats. This allowed rats to earn food pellets in both components by pressing a lever and receive food pellets in one component without pressing a lever. Tolerance was expected to develop to a lesser extent in components with non-contingent food pellets compared to components without non-contingent food pellets. Tolerance was also expected to develop to a lesser extent in components with non-contingent food pellets for rats in the More-Enriched Group compared to rats in the Less-Enriched Group. That was not the case in the present study as tolerance developed to a similar extent in components with and without non-contingent food pellets for rats in both groups. Some potential reasons for these results are discussed below.

Dallery and Lancaster (1999) noted that there was substantial variability in the values of $R_{\mathrm{o}}$ obtained during baseline conditions across individual rats in their study. Because values of $R_{O}$ can vary widely across subjects, even under seemingly equivalent conditions, it is possible that results from the present study were influenced by variations in how the environmental context was experienced by individual rats. Measures of $R_{\mathrm{o}}$ were not obtained in the present experiment because only two schedule values were used in the present experiment. Typically, measures of $R_{\mathrm{o}}$ are obtained under a multiple schedule context in which five or more schedule values are presented during a session. Because measures of $R_{\mathrm{o}}$ were not obtained in the present study, it is not possible to know if providing non-contingent food pellets influenced values of $R_{\mathrm{o}}$, or how variations in $R_{\mathrm{o}}$ influenced the development of tolerance. Future research could address this issue by measuring how $R_{o}$ changes in response to manipulations that alter the environmental context and determine if those changes in $R_{\mathrm{o}}$ are related to the development of tolerance.

Although components with non-contingent food pellets were enriched relative to components without non-contingent food pellets, it is possible that rats were not able to 
discriminate the difference in the environmental contexts. This account may be plausible for rats in the Less-Enriched Group where, during baseline, an additional 1 to 8 food pellets were provided non-contingently, but it seems less plausible for rats in the More-Enriched Group where, during baseline, an additional 12 to 26 food pellets were provided non-contingently. Further, relatively more non-contingent food pellets were provided during the acute and chronic phases due to increases in session length; up to 8 food pellets were provided non-contingently for rats in the Less-Enriched Group, and up to 30 food pellets were provided non-contingently for rats in the More-Enriched Group. It is possible that tolerance would have developed to a different extent across components had non-contingent food pellets been provided at rates different than those used in the present study, or if different stimuli had been used to signal the delivery of contingent and non-contingent food pellets. Recall, however, that components with and without non-contingent food pellets were associated with different levers. Further research could explore how these issues might influence the development of tolerance.

Dallery and Lancaster (1999) also found that tolerance developed to a greater extent in components with smaller VI values (i.e., schedules with a higher rate of reinforcement) compared to components with larger VI values (i.e., schedules with a lower rate of reinforcement). Specifically, tolerance developed to a greater extent in the VI 8-s and VI 17-s components, and to a lesser extent in the VI 55-s, VI 150-s, and VI 250-s components. Although schedule-parameter-value related tolerance reliably occurs under ratio schedules (Branch, 1990; Hoffman et al., 1987; Hughes et al., 1996; van Haaren and Anderson, 1994), it does not occur commonly under interval schedules (Branch; Schama and Branch, 1989). The exact reasons for this discrepancy are not entirely clear, but it may be related to the number of responses required for reinforcement and the context in which schedules are arranged. A study reported by Nickel 
et al. (1993) speaks to this issue. In their study, key pecking for grain was maintained by a FR 125 schedule for one group of pigeons. For another group of pigeons, key pecking for grain was maintained by a FR 125 schedule that alternated across sessions with a multiple schedule consisting of a FR 125 component and a FR 250 component. Tolerance to cocaine's ratedecreasing effects did not occur for pigeons in either group under just the FR 125 schedule. For the latter group, however, tolerance did occur under the FR 125 schedule when it alternated with the FR 250 schedule under the multiple schedule. These findings underscore the role that the reinforcement-schedule context plays in tolerance development (see also Smith, 1986b), and also provide evidence that there could be boundary conditions in terms of whether tolerance will develop under specific values of certain schedules of reinforcement. The present study lacked a control condition to assess the extent to which tolerance develops under a VI 60-s schedule independent of a context in which non-contingent food pellets were provided. The extent to which the present findings are due to the use of an interval schedule, the specific value of the interval schedule used, or the context in which the VI schedules were arranged remains unknown (but see Branch). Future research could investigate how providing non-contingent food pellets affects the development of tolerance under interval schedules with values different than those used in the present study, and how the context in which those schedules are presented affects the development of tolerance. It would also be of interest to determine if providing non-contingent food pellets influences the development of schedule-parameter-value related tolerance commonly observed under FR schedules. It is possible that providing non-contingent food pellets might supplement the cost associated with regaining reinforcement lost following injection of a rate-decreasing drug dose under FR schedules where reinforcement is typically dependent on multiple responses as opposed to just one response with interval schedules. 
An important feature of the present study is that the repeatedly injected dose of $d$ amphetamine was one that decreased the total number of food pellets earned by at least $50 \%$ compared to when saline was injected acutely. This was done to increase the probability that tolerance would develop (i.e., reinforcement loss would occur; see Schuster et al., 1966) so that effects of providing non-contingent food pellets on the development of tolerance could be assessed. Providing non-contingent food pellets was hypothesized to make tolerance less likely to develop as providing non-contingent food pellets was expected to supplement the decrease in the food pellets earned by lever pressing. It was therefore critical to increase the probability that tolerance would develop. The individually selected repeated dose of $d$-amphetamine reduced the total number of food pellets earned (i.e., how much reinforcement loss occurred) to a similar extent for most rats. Although the development of tolerance was not related to the amount of reinforcement loss that occurred following acute injections of the individually selected repeated dose, it was related to the size of the repeatedly administered dose of $d$-amphetamine. There was a statistically significant negative correlation between dose size and tolerance ratio for components with and without non-contingent food pellets when data were collapsed across groups. For example, the repeatedly injected dose of $d$-amphetamine for rat M5 was $0.8 \mathrm{mg} / \mathrm{kg}$ $d$-amphetamine. This was the smallest dose that was repeatedly injected for any rat, and tolerance developed to the greatest extent for this rat. The repeatedly injected dose selected for rat L4 was $2.3 \mathrm{mg} / \mathrm{kg} d$-amphetamine. This was one of the larger doses selected to be repeatedly injected, and tolerance occurred to a minimal extent in the component with non-contingent food pellets while sensitization occurred in the component without non-contingent food pellets. Note, however, that when data from either rat M5 or L4 were excluded from analysis, dose size was not significantly correlated with tolerance ratios. Although the correlation between dose size and 
tolerance ratios in the present study was due primarily to two rats, other research has reported that repeated injections of larger drug doses often results in sensitization whereas repeated injections of smaller drug doses often results in tolerance (Branch, 1990; Hoffman et al., 1987; Reith, 1986). That tolerance did not develop for rat L4 could also be due to changes in leverpress rates during the chronic phase, as lever-press rates for this rat when saline was tested were higher in the chronic phase compared to the acute phase. Lever-press rates for other rats remained relatively similar throughout the study. Future research could examine more systematically the extent to which dose size influences the development of tolerance under conditions similar to those used in the present study. It would also be of interest to examine the extent to which providing non-contingent food pellets influences the development of tolerance to repeated administration of a drug dose that does not produce a loss in reinforcement (see Minervini and Branch, 2013).

It has been suggested that a behavioral-momentum analysis might be predictive of tolerance development (Minervinni and Branch, 2013; Poling et al., 2000). According to behavioral-momentum theory, the strength of a response is reflected by the stimulusreinforcement contingency, not the response-reinforcement contingency. Responses occurring in a context with higher reinforcement rates are therefore thought to be more resistant to change when disruptors such as pre-feeding or extinction are introduced compared to responses occurring at a higher rate (Nevin et al., 1990). The present experiment provides some information relevant to this theory. The response-reinforcement contingency was the same in each component of the multiple schedule, and lever-press rates tended to vary across rats. The stimulus-reinforcer contingency, however, was different across components. In one component, non-contingent food pellets were provided. In the other component they were not. Thus, the 
stimulus-reinforcer contingency was higher in components with non-contingent food pellets compared to components without non-contingent food pellets. According to behavioralmomentum theory, responding should be less disrupted by $d$-amphetamine in components with higher stimulus-reinforcement pairings (i.e., components with non-contingent food pellets) compared to components with lower stimulus-reinforcement pairings (i.e., components without non-contingent food pellets) regardless of response rates. In the present study, lever-press rates and reinforcement rates based on the total number of food pellets provided in a component were not systematically related to the extent to which responding was disrupted by $d$-amphetamine, or the extent to which tolerance developed. Because measures of response strength such as response rates or reinforcement rates were not related to the extent to which tolerance developed it does not appear that the development of tolerance can be accounted for using a behavioralmomentum theory. Such a finding is consistent with research showing that pharmacological agents disrupt responding differently than pre-feeding or extinction (Cohen, 1986), and that tolerance development is not systematically related to response rates (Branch, 1990; Hughes et al., 1996; 2005) or reinforcement rates (Branch; Schama and Branch, 1989).

\section{Response-bout Analysis}

Aggregated measures of responding can sometimes mask order that might be revealed by using more detailed analyses (Branch \& Gollub, 1974; Shull et al., 2001). A secondary aim of this study was to use a response-bout analysis to try and elucidate possible behavioral mechanisms responsible for tolerance development. It has been suggested that responding may be bi-modal and consist of periods of engagement followed by periods of disengagement (Gilbert, 1958; Shull et al.). Shull et al. and others have found that plotting IRT distributions as log-survivor functions can reveal orderly behavior-environment relations that are obscured by 
aggregated measures such as response rates. These log-survivor functions of IRT distributions often show broken-stick patterns, which indicate that responding sometimes occur in bouts of responses with relatively short IRTs (i.e., within-bout responses) separated by responses with relatively long IRTs (i.e., bout-initiation responses), and behavioral effects of drugs have been shown to differentially affect these two types of responses (Johnson et al., 2011; but see Bennett et al, 2007). Methods described by Shull (2004) were therefore used to analyze log-survivor functions of IRT distributions and measure bout-initiation and within-bout rates in an attempt to provide additional information about the development of tolerance.

In the current study, log-survivor functions with a clear broken-stick appearance were not reliably obtained. Further, estimates of bout-initiation and within-bout rates were the same in components with the same schedule for a majority of rats during the baseline, acute, and chronic phases. Bout-initiation and within-bout rate estimates were the same in so many cases because the log-survivor functions of IRT distributions were described by a single-exponential function better than a double-exponential function. This is problematic because it impossible to classify IRTs as bout-initiation or within-bout responses. The primary goal of the present study was to determine how providing non-contingent food pellets affects the development of tolerance. Because classifying IRTs as bout-initiation or within-bout responses was not possible using the methods described by Shull (2004), it was not possible to compare accurately how bout-initiation and within-bout responses changed across components during the acute and chronic phases, or to determine whether such changes were related to the development of tolerance. Some reasons why bout-initiation and within-bout responses were indistinguishable in so many cases in the present study are discussed below. 
Although log-survivor functions produced by IRT distributions with a broken-stick appearance have been obtained across a variety of response topographies (i.e., nose poking, lever pressing, and masticating) with different species (i.e., mice, rats, and humans) (Brackney et al., 2011; Gerstner \& Cianfarani, 1998; Johnson et al., 2009; 2011; Shull and Grimes, 2003), several studies using pigeons that key pecked for food have failed to find a clear broken-stick pattern (Bennett et al., 2007; Bowers et al., 2008; Podlesnik et al., 2006). Although nuanced procedural differences could have contributed to the high number of cases in which estimates of boutinitiation and within-bout responses were the same, such an account seems unlikely given that many of studies in which IRTs were readily distinguished as being bout-initiation or within-bout responses used rats that lever pressed for food pellets under schedules of reinforcement similar to those used in the present study (Brackney et al; Shull and Grimes).

The present findings could also have been influenced by IRT sample size. For example, Shull et al. (2002) obtained unreliable parameter estimates when examining log-survivor functions of IRT distributions across extinction sessions during which response rates decreased. In a simulation, Bennett (2013) also showed that estimates of bout-initiation and within-bout rates became more variable as IRT sample size decreased. These studies suggest that a relatively large number of IRTs may be needed to obtain reliable and valid parameter estimates. In the present study, IRTs were collapsed across sessions to reduce the influence outlying IRTs had on parameter estimates. This increased the IRT sample size and produced better fits by the doubleexponential equation compared to when data from single sessions were fit to the equation. Sample-size limitations likely influenced the parameter estimates obtained during the acute and chronic phases as $d$-amphetamine produced a dose-dependent decrease in lever-press rates, but such an explanation does not account for the parameter estimates obtained during baseline when 
more lever presses occurred and data were collapsed across the last six stable sessions. Lever pressing for a majority of rats during baseline (and other conditions) may have not been bi-modal in nature, and instead composed of several different types of IRT distributions (e.g., Davison, 2004) as evidenced by the multiple breaks often observed in the log-survivor functions of IRT distributions and the fact that a single-exponential equation described the log-survivor functions of IRT distributions better than the double-exponential equation for the majority of rats. Although data from the present study were not well suited for a response-bout analysis, this does not mean that such an analysis could not be used to tease apart the behavioral mechanisms of drug action (see Johnson et al., 2011; Bennett). Future research attempting to tease apart behavioral effects of drugs using a response-bout analysis should arrange conditions so that boutinitiation rates, which have been shown to be influenced by changes in reinforcer properties, and within-bout rates, which have been shown to be influenced by changes in response requirements, are clearly distinguishable.

\section{Conclusion}

In summary, tolerance developed to the rate-decreasing effect of $d$-amphetamine to a similar extent in components with and without non-contingent food pellets. These results indicate that enriching the environment by providing non-contingent food pellets during experimental sessions does not differentially affect the development of tolerance. Although providing non-contingent food pellets did not differentially affect the development of tolerance under the conditions studied in the present experiment that does not mean that it may not influence the development of tolerance under other conditions. The development of tolerance is sensitive to a variety of factors including reinforcement loss, the context in which schedules of reinforcement are arranged, the specific parameters of the schedule used to maintain behavior, 
and features of the drug regime (e.g., Branch, 1990; Hoffman et al., 1987; Nickel et al., 1993; Pinkston and Branch, 2010; Smith, 1986b). How these various features interact to influence the development of tolerance needs to be studied further. For example, it is possible that tolerance might have developed to a different extent across components had other schedules or schedule values been used, if the context in which the schedules were presented had been different, if the environment was enriched using other methods, or if a different drug regimen had been used. Environmental enrichment, which can take many forms (Toth et al., 2011), has protective effects across many stages of drug abuse including acquisition, maintenance, escalation, and extinction (Carroll et al., 2009; Gipson et al., 2011; Stairs \& Bardo, 2009; Stairs et al. 2006; Theil et al., 2011). It remains to be determined how different forms of environmental enrichment influence and interact with variables already known to influence the development of tolerance. 


\section{References}

American Psychiatric Association (2000). Diagnostic and statistical manual of mental disorders. $4^{\text {th }}$ ed. text revision. Washington, DC: American Psychiatric Association.

Belke T. W. \& Heyman, G. M. (1994). Increasing and signaling background reinforcement: Effects on the foreground response-reinforcer relation. Journal of the Experimental Analysis of Behavior, 61, 65-81.

Bennett, J. A., Hughes, C. E., \& Pitts, R. C. (2007). Effects of methamphetamine on response rate: A microstructural analysis. Behavioral Processes, 75, 199-205.

Bennett, J. A. (2013). Assessing the generality of a bout analysis in the description of operant behavior. (Doctoral dissertation). Retrieved from ScholarWorks at WMU (Paper 174.)

Bowers, M. T., Hill., J., \& Palya, W. L. (2008). Interresponse time structures in variable-ratio and variable-interval schedules. Journal of the Experimental Analysis of Behavior, 90, 345-362.

Brackney, R. J., Cheung, T. H. C., Neisewander, J. L., \& Sanabria, F. (2011). The isolation of motivational, motoric, and schedule effects on operant performance: A modeling approach. Journal of the Experimental Analysis of Behavior, 96, 17-38.

Branch, M. N. (1990). Cocaine tolerance: Interactions among random-ratio and random-interval reinforcement-schedule parameters and repeated exposure to cocaine. Drug Development Research, 20, 19-30.

Branch, M. N. (1991). Behavioral factors in drug tolerance. In I. H. Iversen \& A. Lattal (Eds.), Techniques in the Behavioral and Neural Sciences (Vol. 6): Experimental Analysis of Behavior, Part 2. New York: Elsevier.

Branch, M. N., \& Gollub, L. R. (1974). A detailed analysis of the effects of d-amphetamine on 
behavior under fixed-interval schedules. Journal of the Experimental Analysis of Behavior, 21, 519-539.

Burgress, I. S., \& Wearden, J. H. (1986). Superimposition of response-independent reinforcement. Journal of the Experimental Analysis of Behavior, 45, 75-82

Carroll, M. E., Anker, J. J., Perry, J. L. (2009). Modeling risk factors for nicotine and other drug abuse in the preclinical laboratory. Drug \& Alcohol Dependence, 104, 70-78.

Cohen, S. L. (1986). A pharmacological examination of the resistance-to-change hypothesis of response strength. Journal of the Experimental Analysis of Behavior, 46, 363-379.

Corfield-Summer, P. K., \& Stolerman, I. P. (1978). Behavioral tolerance. In D.E. Blackman \& D.J. Sanger (Eds.), Contemporary research in behavioural pharmacology (pp. 391-448). New York: Plenum.

Dallery, J., \& Lancaster, J. S. (1999). Individual differences in behavioral tolerance to amphetamine and the economic context of reinforcement loss. Behavioural Pharmacology, 10, 257-269.

Dallery, J., \& Soto, P. L. (2004). Herrnstein's hyperbolic matching equation and behavioral pharmacology: Review and critique. Behavioural Pharmacology, 15, 443-459.

Davison, M. (2004). Interresponse times and the structure of choice. Behavioral Process, 66, 173-187.

Davison, M., \& McCarthy, D. (1988). The matching law: A research review. Hillside, NJ: Lawrence Erlbaum.

Dews, P. B. (1955). Studies on behavior. I. Differential sensitivity to pentobarbital of pecking performance in pigeons depending on the schedule of reward. The Journal of Pharmacology and Experimental Therapeutics, 113, 391-401. 
de Villers P. A. (1977). Choice in concurrent schedules and a quantitative formulation of the law of effect. In W.K. Honig \& J.E.R. Staddon (Eds.), Handbook of operant behavior (pp. 233-287). Englewood Cliffs, NJ: Prentice Hall.

Fleshler, M., \& Hoffman, H. S. (1962). A progression for generating variable-interval schedules. Journal of the Experimental Analysis of Behavior, 5, 529-530.

Genovese, R. F., Elsmore, T. F., \& Witkin, J. M. (1988). Environmental influences on the development of tolerance to the effects of physostigmine on schedule-controlled behavior. Psychopharmacology, 96, 462-467.

Gerstner, G. E., \& Cianfarani, T. (1998). Temporal dynamics of human masticatory sequences. Physiological Behavior, 64(4), 457-461.

Gilbert, T. F. (1958). Fundamental dimensional properties of the operant. Psychological Review, 65, 272-282.

Gipson, C. D., Beckmann, J. S., El-Maraghi, S., Marusich, J. A., \& Bardo, M. T. (2011). Effects of environmental enrichment on escalation of cocaine self-administration in rats. Psychopharmacology, 214, 557-566.

Goudie, A. J., \& Emmett-Oglesby, M. (1989). Psychoactive drugs: Tolerance and sensitization. Humana Press, Clifton, NJ.

Herrnstein, R. J. (1970). On the law of effect. Journal of the Experimental Analysis of Behavior, 13, 243-266.

Herrnstein, R. J. (1974). Formal properties of the matching law. Journal of the Experimental Analysis of Behavior, 21, 159-164.

Heyman, G. M. (1983). A parametric evaluation of the hedonic and motoric effects of drugs: 
Pimozide and amphetamine. Journal of the Experimental Analysis of Behavior, 40, $113-$ 122.

Hill, J. C., Herbst, K., Sanabria, F. (2012). Characterizing operant hyperactivity in the Spontaneously Hypertensive rat. Behavioral and Brain Functions, 8, 5.

Hoffman, S. H., Branch, M. N., \& Sizemore, G. M. (1987). Cocaine tolerance: Acute versus chronic effects as dependent upon fixed-ratio size. Journal of the Experimental Analysis of Behavior, 47, 363-376.

Hughes, C. E., Pitts, R. C., \& Branch, M. N. (1996). Cocaine and food deprivation: Effects on food-reinforced fixed-ratio performance in pigeons. Journal of the Experimental Analysis of Behavior, 65, 145-158.

Hughes, C. E., Sigmon, S. C., Pitts, R. C., \& Dykstra, L. A. (2005). Morphine tolerance as a function of ratio schedule: Response requirement or unit price? Journal of the Experimental Analysis of Behavior, 83, 281-296.

Johnson, J. E., Bailey, J. M., \& Newland, C. M. (2011). Using pentobarbital to assess the sensitivity and independence of response-bout parameters in two mouse stains. Pharmacology, Biochemistry, and Behavior, 97, 470-478.

Johnson, J. M., Pesek, E. F., \& Newland, M. C. (2009). High rate operant behavior in two mouse strains: A response-bout analysis. Behavioural Processes, 81, 309-315.

Macaskill, A. C., \& Branch, M. N. (2012). Tolerance to cocaine's effects on schedule controlled behavior: Role of delay between pause-ending responses and reinforcement. Pharmacology, Biochemistry and Behavior, 100, 616-623.

McDowell, J. J. (1988). Matching theory in natural human environments. The Behavior Analyst, 11, 95-109. 
Minervini, V., \& Branch, M. N. (2013). Tolerance to cocaine's effects following chronic administration of a dose without detected effects on response rate or pause. Journal of the Experimental Analysis of Behavior, 100, 316-332.

Nevin, J. A., Tota, M. E., Torquato, R. D., \& Shull, R. L. (1990). Alternative reinforcement increases resistance to change: Pavlovian or operant contingencies? Journal of the Experimental Analysis of Behavior, 53, 359-379.

Nickel, M., Alling, K., Kleiner, M., \& Poling, A. (1993). Fixed-ratio size as a determinant of tolerance to cocaine: Is relative or absolute size important? Behavioural Pharmacology, 4, 471-478.

Pinkston, J. W., \& Branch, M. N. (2010). Acute and chronic effects of cocaine on the spontaneous behavior of pigeons. Journal of the Experimental Analysis of Behavior, 94, 25-36.

Podlesnik, C. A., Jimenez-Gomez, C., Ward, R. D., \& Shahan, T. A. (2006). Resistance to change of responding maintained by unsignaled delays to reinforcement: A response-bout analysis. Journal of the Experimental Analysis of Behavior, 85, 329-347.

Porritt, M., Arnold, M., \& Poling, A. (2007). Cocaine and automaintained responding in pigeons: Rate-reducing effects and tolerance thereto with different CS - US paring probabilities. Pharmacology, Biochemistry and Behavior, 87, 405-411.

Rachlin, H., \& Baum, W. M. (1972). Effects of alternative reinforcement: Does the source matter? Journal of the Experimental Analysis of Behavior, 18, 231-241.

Reed, D. D, \& Kaplan, B. A. (2011). The matching law: A tutorial for practitioners. Behavior Analysis in Practice, 4(2), 15-24. 
Reed, P. (2011). An experimental analysis of steady-state response rate components on variable ratio and variable interval schedules of reinforcement. Journal of Experimental Psychology: Animal Behavior Processes, 37, 1-9.

Reith, M. E. A (1986). Effect of repeated administration of various doses of cocaine and WIN 35,065-2 on locomotor behavior of mice. European Journal of Pharmacology, 130, 6567.

Schama, K. F., \& Branch, M. N. (1989). Tolerance to effects of cocaine on schedule-controlled behavior: Effects of fixed-interval schedule parameter. Pharmacology, Biochemistry and Behavior, 32, 267-274.

Schuster, C. R. (1978). Theoretical Basis of Behavioral Tolerance: Implications of the Phenomenon for Problems of Drug Abuse. In N.A. Krasnegor (Series Ed.), National Institute on Drug Abuse Research Monograph Series: Vol 18. Behavioral Tolerance: Research and Treatment Implications (pp. 4-17). Washington, DC.

Schuster, C. R., Dockens, W. S., \& Woods, J. H. (1966). Behavioral variables affecting the development of amphetamine tolerance. Psychopharmacology, 9, 170-182.

Shull, R. L. (2004). Bouts of responding on variable-interval schedules: Effects of deprivation level. Journal of the Experimental Analysis of Behavior, 81, 155-167.

Shull, R. L., Gaynor, S. T., \& Grimes, J. A. (2001). Response rates viewed as bouts of engagement: Effects of relative reinforcement and schedule type. Journal of the Experimental Analysis of Behavior, 75, 247-274.

Shull, R. L., Gaynor, S. T., \& Grimes, J. A. (2002). Response rate viewed as engagement bouts: Resistance to extinction. Journal of the Experimental Analysis of Behavior, 77, 211-231. 
Shull, R. L., \& Grimes, J. A. (2003). Bout of responding from variable-interval reinforcement of lever pressing by rats. Journal of the Experimental Analysis of Behavior, 80, 159-171.

Shull, R. L., Grimes, J. A., \& Bennett, J. A. (2004). Bouts of responding: The relation between bout rate and the rate of variable interval performance. Journal of the Experimental Analysis of Behavior, 81, 65-83.

Smith, J. B. (1986a). Effects of fixed-ratio length on the development of tolerance to decreased responding by 1-nantradol. Psychopharmacology, 90, 259-262.

Smith, J. B. (1986b). Effects of chronically administered $d$-amphetamine on spaced responding under multiple and single-component schedules. Psychopharmacology, 88, 296-300.

Smith, J. B. (1990). Effects of fixed-ratio requirement on observed tolerance to decreased responding by clonidine. Pharmacology, Biochemistry and Behavior, 36, 993-996.

Stafford, D., \& Branch, M. N. (1996). Relations between dose magnitude, subject sensitivity, and the development of tolerance to cocaine-induced behavioral disruptions in pigeons. Behavioural Pharmacology, 7, 324-333.

Stairs, D. J., Klein, E. D., \& Bardo, M. T. (2006). Effects of environmental enrichment on extinction and reinstatement of amphetamine self-administration and sucrose-maintained responding. Behavioural Pharmacology, 17, 597-604.

Stairs, D. J., \& Bardo, M. T. (2009). Neurobehavioral effects of environmental enrichment and drug abuse vulnerability. Pharmacology, Biochemistry and Behavior, 92, 377-382.

Stewart, J., \& Badiani, A. (1993). Tolerance and sensitization to the behavioral effects of drugs. Behavioural Pharmacology, 4, 289-312.

Thiel, K. J., Engelhardt, B., Hood, L. E., Peartree, N. A., Neisewander, J. L. (2011). The interactive effects of environmental enrichment and extinction interventions in 
attenuating cue-elicited cocaine-seeking behavior in rats. Pharmacology, Biochemistry, and Behavior, 97, 595-602.

Toth, L. A., Kregel, K., Leon, L., \& Musch, T. I. (2011). Environmental enrichment of laboratory rodents: The answer depends on the question. Comparative Medicine, 61 (4), 314-321.

van Haaren, F., \& Anderson, K. G. (1994). Behavioral effects of acute and chronic cocaine administration in male and female rats: Effects of fixed-ratio schedule parameters. Behavioural Pharmacology, 5, 607-614.

Williams, B. A. (1988). Reinforcement, choice, and response strength. In A.C. Atkinson, R.J. Herrnstein, G. Lindzey, R.D. Luc (Eds.), Stevens’ Handbook of Experimental Psychology, Vol. 2 (pp. 167-244). New York: Wiley.

Wolgin, D. L. (1989). The role of instrumental learning in behavioral tolerance to drugs. In A.J. Goudie, M.W. Emmett-Oglesby (Eds.), Psychoactive drugs: Tolerance and sensitization (pp. 17-114). Clifton, NJ: Humana Press.

Wolgin, D. L. (2000). Contingent tolerance to amphetamine hypophagia: New insights into the role of environmental context in the expression of stereotypy. Neuroscience and Biobehavioral Reviews, 24, 279-294.

World Health Organization (2011). International classification of diseases. $10^{\text {th }}$ edition. World Health Organization, Geneva. 